A Division of North American Aviation, Inc.

\title{
JUN $>81961$
}

Do not removr this sheet
NAA-SR-MEMO -6270
This document contains 49 pages

This is copy of series

\section{$N A A-S R-M E M O S$ are working papers and may be expanded, modified, or withdrawn at any time, and are intended for intemal use only.}

This report may not be published without the approval of the Patent Branch, AEC.

\section{LEGAL NOTICE}

This report was prepored as on occount of Government sponsored work. Neither the United States, nor the Commission, nor any person acting on behalf of the Commission:

A. Makes any warranty or repiesentation, express or implied, with respect to the occuracy, completeness, or usofulness of the information contained in this report, or thet the use of any information, apparatus, mothod, or process disclosed in this report moy not infringe privatoly owned rights; or

B. Assumes any liabilities with respect to the use of, or for damages resulting from the use of information, apparotus, method, or process disclosed in this report.

As used in the above, "porson acting on bohalf of the Commission" includes any omployee or contractor of the Commission to the oxtent that such employee or contractor propares, handles or distributes, or provides access to, any information pursuant to his employment or contract with the Commission. 


\section{DISCLAIMER}

This report was prepared as an account of work sponsored by an agency of the United States Government. Neither the United States Government nor any agency Thereof, nor any of their employees, makes any warranty, express or implied, or assumes any legal liability or responsibility for the accuracy, completeness, or usefulness of any information, apparatus, product, or process disclosed, or represents that its use would not infringe privately owned rights. Reference herein to any specific commercial product, process, or service by trade name, trademark, manufacturer, or otherwise does not necessarily constitute or imply its endorsement, recommendation, or favoring by the United States Government or any agency thereof. The views and opinions of authors expressed herein do not necessarily state or reflect those of the United States Government or any agency thereof. 


\section{DISCLAIMER}

Portions of this document may be illegible in electronic image products. Images are produced from the best available original document. 


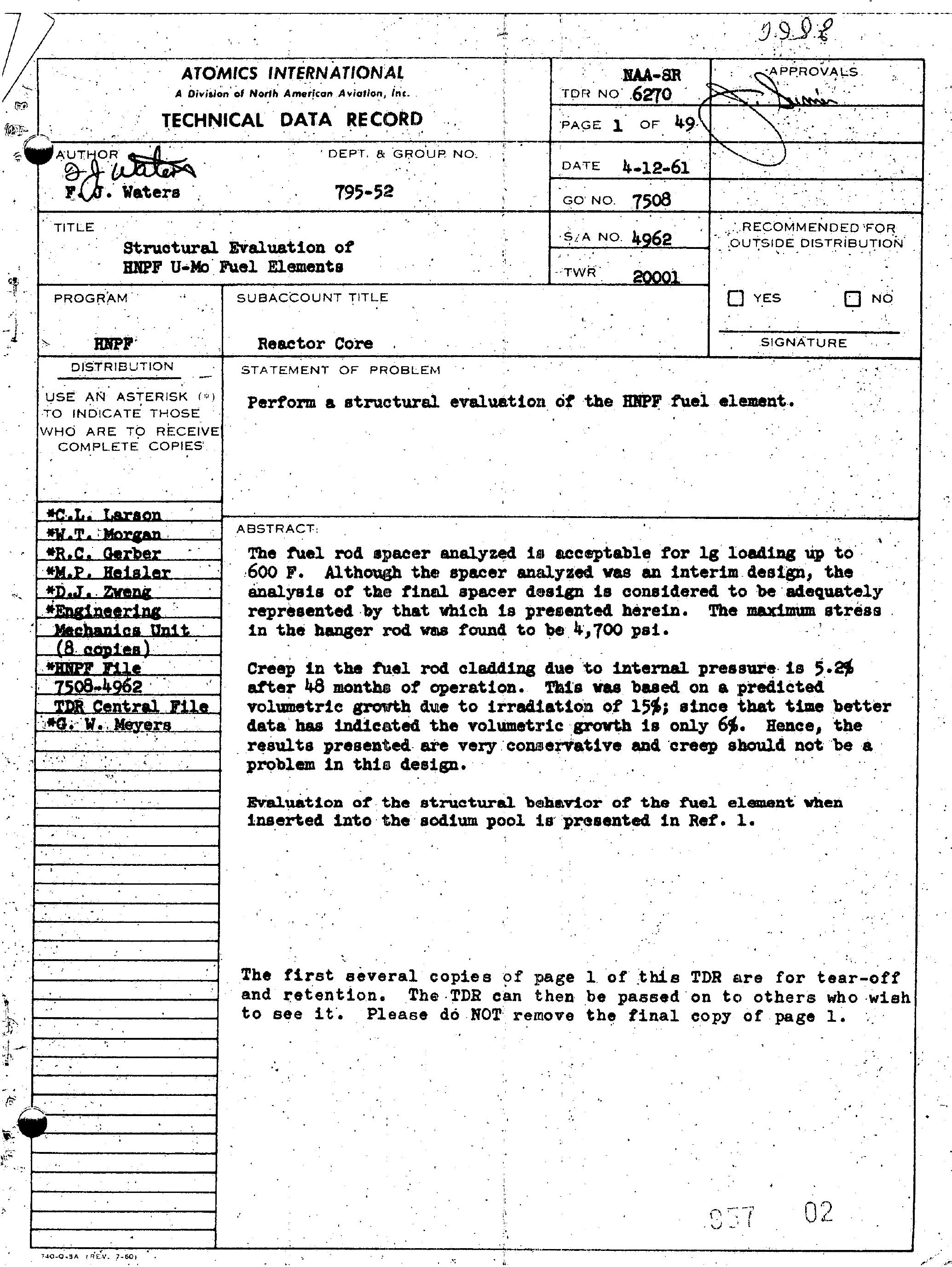




\section{ATOMICS INTERNATIONAL}

A Division of North American Aviation, Inc.

\section{Spacer}

The opacer to be analyzed is shown below.

(1) Inner Spacer

(2) Side Spacer

(3) Bottom Spacer

(4) Outer Brace

DATE

PAGE 2 OF
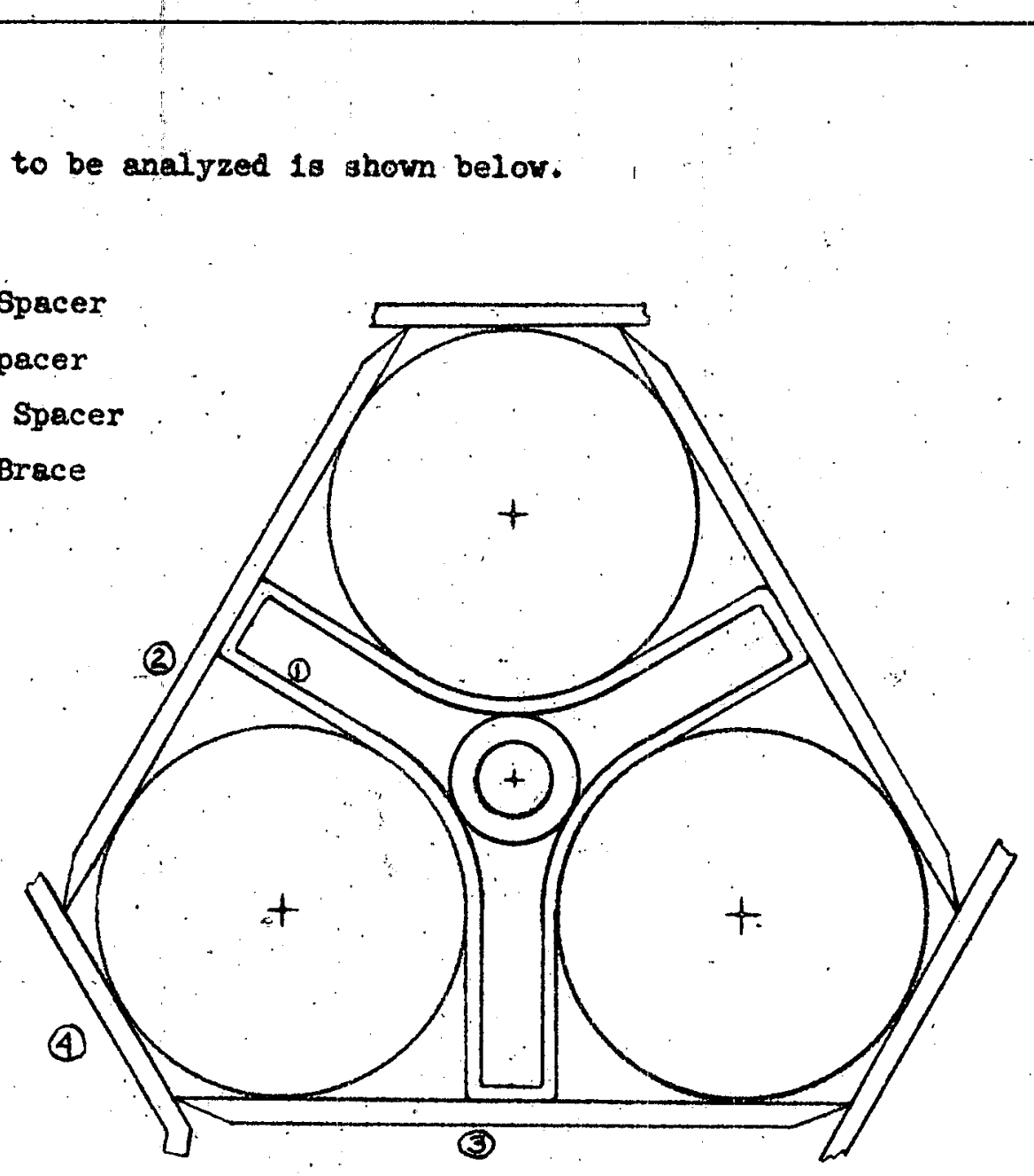

The Inner spacer wll be checked first to see how much lood it is able to transfer to the outer epacer. It is assumed that the inner spacer will only transer lowd to the two adjoining side ppacers as shown below.

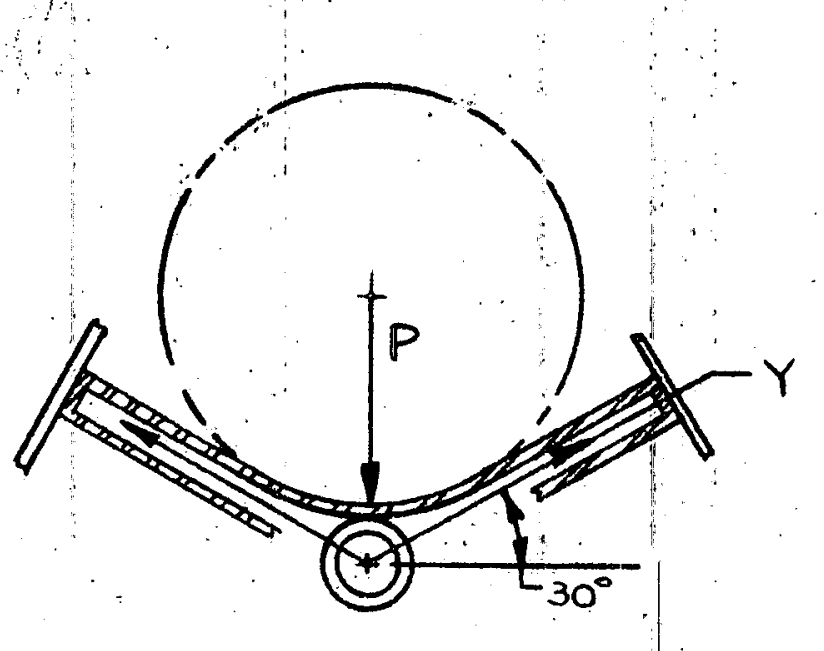




\section{ATOMICS INTERNATIONAL}

A Division of North American Aviation, Ine.

NO. TDR 6270

DATE Apr11 12, 1961

PAGE 4 OF

The vert1cal component of the deflection of the slde spacer is given by:

$$
\delta_{v}=\delta \cos 60^{\circ}=1.785 \times 10^{-3} 1 \mathrm{n} \text {. }
$$

The vertical deflection of the bottoin spacer subjected to the loading of two fuel rods as shown on Page 2 is,

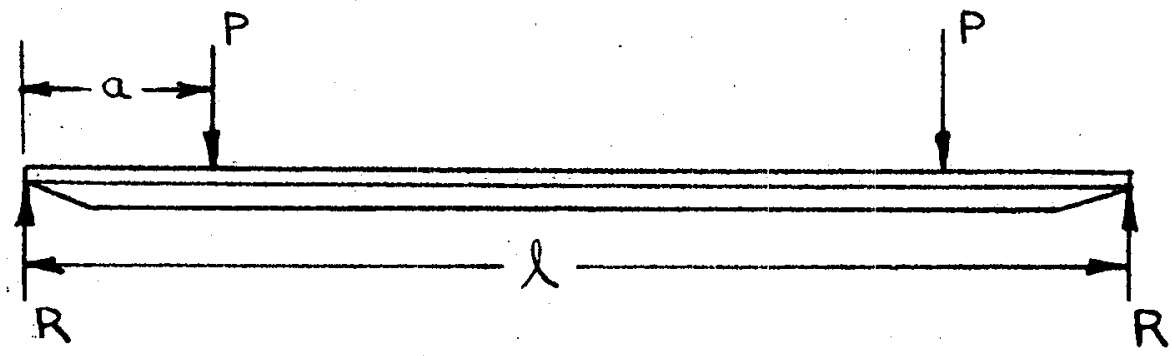

The deflection 18 given by:

$$
\begin{aligned}
& \delta=\frac{P e}{6 E I}\left[\frac{3 f^{2}}{4}-a^{2}\right] \quad \text { (Ref. 2) } \\
& \text { Where: } \begin{aligned}
E & =28 \times 10^{6} \mathrm{ps} \\
\ell & =1.225 \mathrm{in} . \\
a & =0.2 \mathrm{in.} \\
I & =766.1 \times 10^{-9} \mathrm{in.}^{4}
\end{aligned}
\end{aligned}
$$

Therefore,

$$
\begin{aligned}
& \delta=\frac{2 \times .2 \times 10^{3}}{6 \times 28 \times 766.1}\left[\frac{3}{4} \times 1.5-0.04\right] \\
& \delta=3.37 \times 10^{-3} \mathrm{in} .
\end{aligned}
$$




\section{ATOMICS INTERNATIONAL}

A Division of North American Aviation, Inc.
NO. $\operatorname{Tan} 6270$

DATE

Apr11 12, 1961

PAGE OF

Bince this deflection 18 lerger than the vertical component of the deflection of the side specer, it substantiates the assumption that the lnner spacer will transfer 1ts losd to the two side spaceris rather than thru the adjoining fuel rods to the bottom spacer.

Die to the outer and Inner braces, the side spacer vill also see compressive loading along 1 ts axis. The allowable value of thls loed w111 be determined considering the member as a beam column. For the two pound center load ve have:

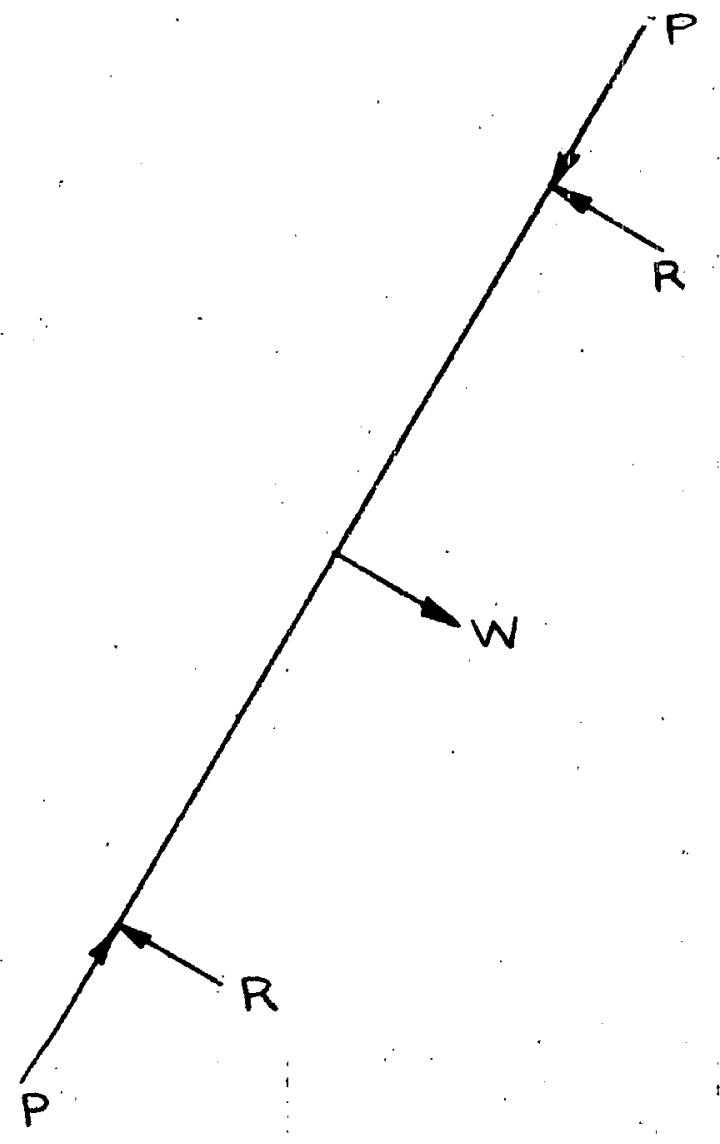

Roark (Ref. 3) gives the following formulas for this case.

$$
H_{\text {mex }}=\frac{1}{2} \mathrm{HJ} \cdot \tan \frac{U}{2}
$$

Where: $M .=$ Bending moment

$$
\begin{aligned}
& j=\sqrt{\frac{E I}{\mathrm{P}}} \\
& \mathrm{v}=\frac{\&}{J}
\end{aligned}
$$


The stress 1s;

$$
\nabla=\frac{P}{A}+\frac{M C}{I}
$$

Choosing: $\sigma=24,000$ pis (The Elastic linlt).

$$
\begin{aligned}
& \sigma=\frac{P}{A}+\frac{c}{I}\left[\frac{1}{2} \text { Hg } \tan \frac{U}{2}\right] \\
& 24 \times 10^{3} \mathrm{AI}=\mathrm{PI}+\frac{1}{2} \text { WJCA } \tan \frac{\mathrm{U}}{2} \\
& A=39.35 \times 10^{-4} 10^{2} \quad \text { (see Appondix A) } \\
& I=766.1 \times 10^{-9} \mathrm{in.}^{4} \\
& c=2.36 \times 10^{-2} \mathrm{ln} \text {. } \\
& W=21 b \\
& l=1.225 \mathrm{in} \text {. }
\end{aligned}
$$

Eraluation of the above equation after subititution of the constants gives the final form:

$$
\frac{[94.4-\mathrm{P}] \mathrm{P}^{\frac{1}{2}}}{562}=\tan 0.132 \mathrm{p}^{\frac{1}{2}}
$$

Solution of this transcendental equation (Bee Appendix B) ylelds:

$$
P_{\text {allowable }}=13.751 \mathrm{~b}
$$

The outer brace w11l now be enalyzed to deternine what horfzontal lood w11 be transferred Into the bottom spacer. For this case $1 t$ will be assumed that 13 fuel rods moving laterally will transfer the load to $81 x$ side spacers as shown below.

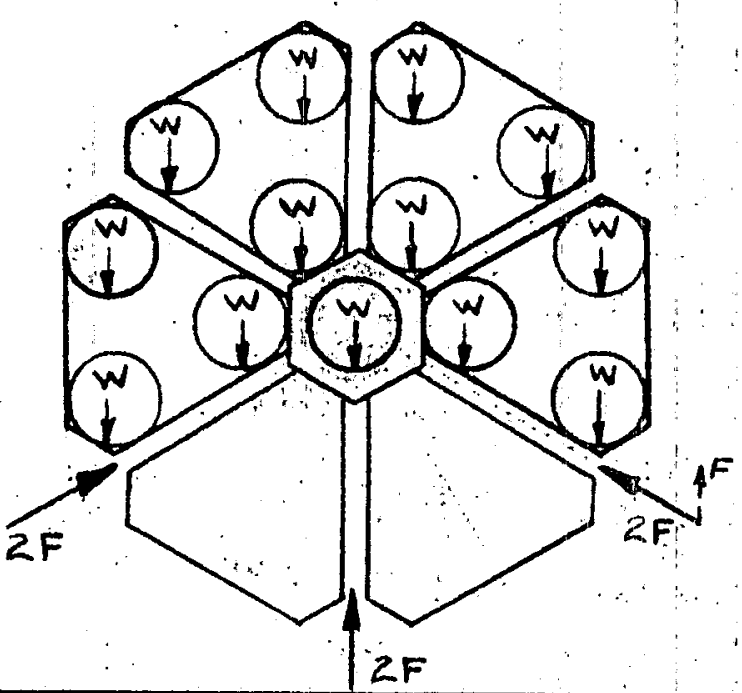




\section{Therefore, each outer brace 111 see the loading slituation show belov.}

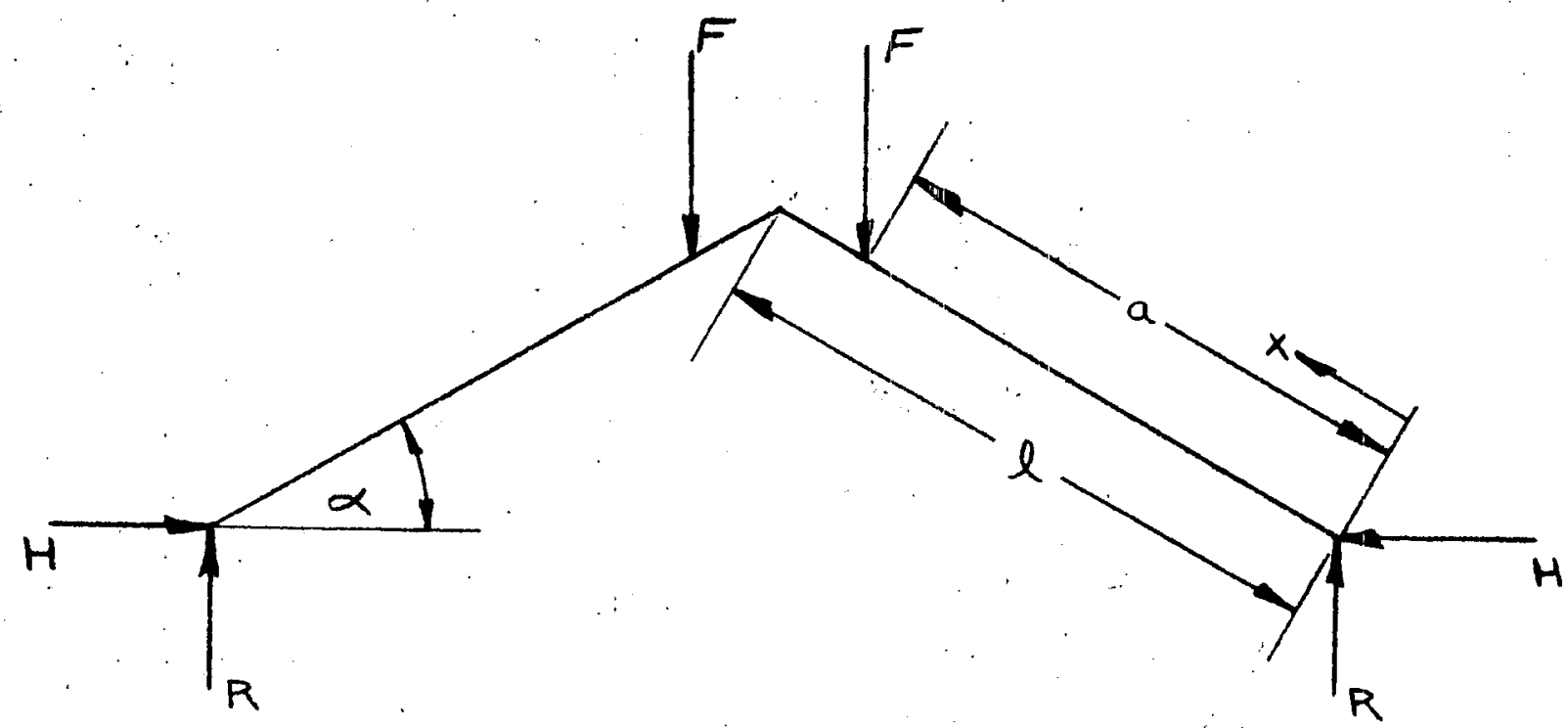

$$
\begin{aligned}
& F=\frac{F W}{4} \\
& F=\frac{(13)(2)}{4}=6.510 \\
& \alpha=30^{\circ}
\end{aligned}
$$

The moment is given by:

$$
\begin{aligned}
& M_{x}=R x \cos \alpha-H x \sin \alpha \quad(\text { from } x=0 \text { to } x=a) \\
& \left.M_{x}=R x \cos \alpha-H x \sin \alpha-F(x-a) \cos \alpha \text { (from } x=a \text { to } x=l\right)
\end{aligned}
$$

From symetry, $R=\mathbb{P}$. 
Therefore,

$$
U=2\left\{\frac{1}{2 \operatorname{lgI}}\left[\int_{0}^{a}(F x \cos \alpha-H x \sin \alpha)^{2} d x+\int_{1}^{l}(F a \cos \alpha-F x \sin \alpha)^{2} d x\right]\right\}
$$

The horizontal force, $\mathrm{H}$, w1ll be a maximum if it 1 is assumed that the horizontal movenent is zero. Therefore,

$$
\begin{aligned}
\delta_{\mathrm{H}}=\frac{\partial U}{\partial H}=0 & =\int_{0}^{a}[\mathrm{Fx} \cos \alpha-\operatorname{tat} \operatorname{cin} \alpha][-x \sin \alpha] d x \\
& +\int_{a}^{l}[\mathrm{Fe} \cos \alpha-\sin \sin \alpha][-x \sin \alpha] d x
\end{aligned}
$$

Solution of the above ylelds,

$$
H=\frac{p}{2} \frac{\cos \alpha}{\sin \alpha}\left[\frac{3 a}{l}-\left(\frac{a}{l}\right)\right]^{3}
$$

$\therefore:$ For, $\quad a=0.372 \mathrm{ln}$.

$$
\begin{aligned}
& \ell=0.444 \mathrm{In} . \\
& \alpha=30^{\circ}
\end{aligned}
$$

The above equation gives,

$$
\mathrm{H}=1.67 \mathrm{~F}
$$

The maximm moment on the outer brece would be given by:

$$
\dot{M}_{\max }=\mathrm{B} l \sin \alpha+F(l-a) \cos \alpha-F l \cos \alpha
$$

or,

$$
M_{\max }=g l \sin \alpha-g \cos \alpha
$$

Subst1tuting the above values for a, $l$, ond $\alpha$ yleids,

$$
M_{\max }=0.3151 \mathrm{n}-1 \mathrm{~b}
$$

The bending stress 18 ,

$$
\sigma_{B}=\frac{M c}{I}
$$


Mere: $c=1.5 \times 10^{-2} 1 \mathrm{n}$.

$$
I=\frac{.375 \times .03^{3}}{12}=8.44 \times 10^{-7} 1 \mathrm{In}^{4}
$$

Therefore,

$$
\sigma_{B}=5,600 \mathrm{ps} 1
$$

Adding to this quantity ia the direct stresis ceised by $B$ and $R$;

$$
\begin{aligned}
& \sigma_{D}=\frac{[\mathrm{B} \cos \alpha+R \sin \alpha]}{A} \\
& \sigma_{D}=\frac{1.67 \times .866+F \times .5}{3.75 \times 3 \times 10^{-3}}=1,1.25 \mathrm{p} 41
\end{aligned}
$$

The above equation gives the direct stress for $0<x<a$.

As conservative estimate, the total streas in tha outer brace is given as;

$$
\sigma_{\text {totel }}=\sigma_{D}+\sigma_{B}=6,725 \mathrm{ps1}
$$

The horizontal component of the load will caupe the bottom apacer to act as a beam column. Relnvestigating this momber we have:

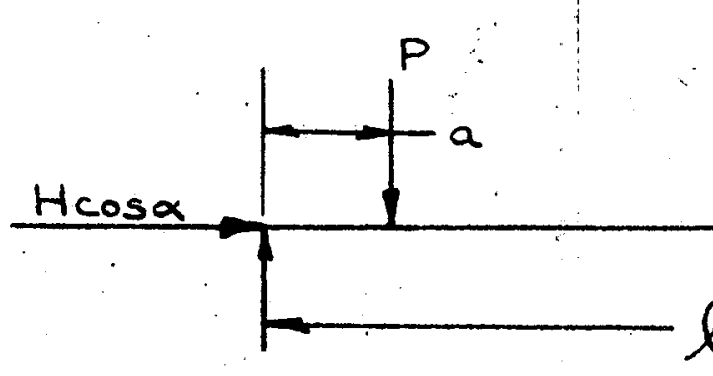

R
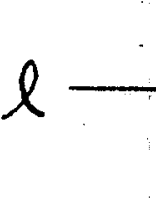

(Hote that the horizontel component acts at the angle $\alpha$, the angle between $H$ and the bottom spacer). 
Roark (Ref. 3) shows that the stress is given by:

$$
\sigma=\frac{H \cos \alpha}{A} \pm \frac{B^{\prime} c}{I}
$$

Where: $A=3.935 \times 10^{-3} \mathrm{fn}^{2}$

$I=766.1 \times 10^{-9} \mathrm{in.}^{4}$

$\alpha=30^{\circ}$

$c_{1}=.0164 \mathrm{in}$.

$c_{2}=.0236 \mathrm{in}$.

As a conservative simpliflcation, this bean will be considered a beam subjected to end couples, $M$ : Ra. For this ense,

$$
M^{\prime}=\frac{M}{1-\beta \frac{(H \cos \alpha) \ell^{2}}{E I}} \quad \text { (Her. 3) }
$$

Were: $\beta=1 / 2$ for a beam wth end couples.

Therefore,

$$
M^{\prime}=\frac{M E I}{E I-\frac{1}{2}(B \cos \alpha) \ell^{2}}
$$

and

$$
\sigma=\frac{H \cos 30^{\circ}}{A} \pm \frac{R E B C}{\operatorname{RII}-0.5\left(H \cos 30^{\circ}\right) l^{2}}
$$

For $\mathrm{H}=1.67 \mathrm{~F}=10.85 \mathrm{ib}$

$$
\begin{aligned}
& E=28 \times 10^{6} \mathrm{ps1} \\
& R=21 \mathrm{~b} \\
& l^{2}=1.5 \mathrm{kn} .^{2}
\end{aligned}
$$

We nave,

$$
\sigma=2,390 \pm .7775 \times 10^{6}
$$

On the upper surface there $c=c_{1}$, the stress 18,

$$
\sigma=15,200 \text { ps1 (compression) }
$$


On the lower surface $c=c_{2}$ and the stress is,

$$
\sigma=16,000 \mathrm{psi} \text { (tension) }
$$

The above vglues are for 18 looding at room tenperature. At $600 \mathrm{~F}$, $E=24 \times 10^{6} \mathrm{ps}$.

Therefore,

and

$$
\sigma=16,300 \text { psi (compression on top surface) }
$$

$$
\sigma=17,600 \mathrm{ps} \text { (tension on lower surfiece) }
$$

Since $\sigma_{\text {yeld }}=17,750 \mathrm{ps}$ at $600 \mathrm{~F}$, the apecer is good for If londing up to tempetatures of $600 \mathrm{~F}$.

Fuel Rod

The atresa developed in a fuel rod for the teaperature distribution given below w1ll now be developed.

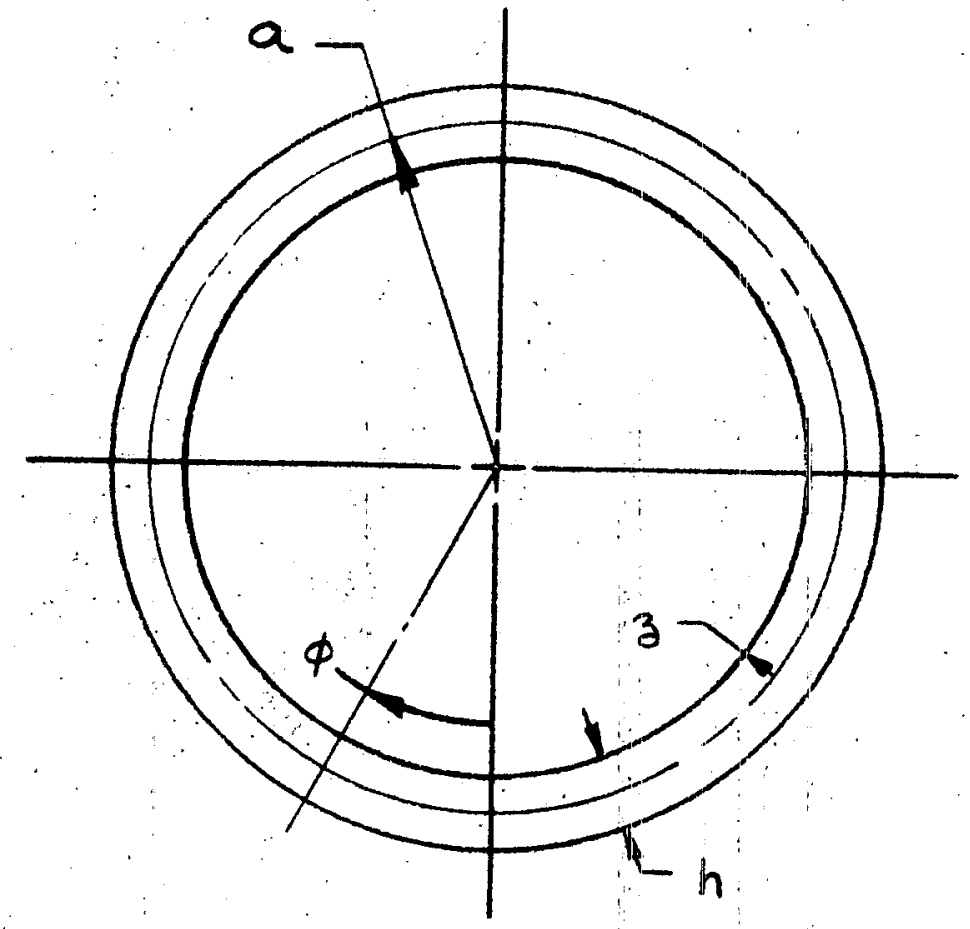

The temperature distribution is given by,

$$
T=974-12.5 \cos \phi+27 \frac{z}{h} \quad \text { (Rer. 4) }
$$


The temperature is a function of $\phi$ and $z$. The avejage temperature in the cladding 1s,

$$
\begin{aligned}
& \bar{T}=\frac{1}{h} \int_{-h / 2}^{h / 2} T d z \quad(\operatorname{Rer} \cdot 5) \\
& \bar{T}=974-12.5 \cos \phi .
\end{aligned}
$$

The equivelent linear terperature drop across the libickness is given by,

$$
\begin{aligned}
& \Delta T=\frac{i 2}{h^{2}} \int_{-h / 2}^{h / 2} T+d z \quad \text { (Ref. 5) } \\
& \Delta T=27 .
\end{aligned}
$$

To evaluate the circumerential stresses due to this circumerential temperature distribution, the method of Condler (Ref. 6) will be epplled.

$$
M_{\phi}=M_{0}+x_{0} y-Y_{0} x
$$

Where:

$$
\begin{aligned}
& x_{0}=\frac{D}{\pi a^{2}}(1+v) \alpha\left[\int_{0}^{2 \pi} \bar{T} \cos \phi \phi-\frac{a}{b} \int_{0}^{2 \pi} \Delta T \cos \phi \alpha \phi\right] \\
& Y_{0}=\frac{D}{\pi_{a}^{2}}(1+\nu) \alpha\left[\int_{0}^{2 \pi} \bar{T} \sin \alpha \phi-\frac{\theta}{h} \int_{0}^{2 \pi} \Delta T \sin \phi d \phi \phi\right] \\
& M_{0}=\frac{D}{\pi_{a}}(1+\nu) \alpha\left[-\int_{0}^{2 \pi} \bar{T} \cos \phi \alpha \phi+\frac{a}{2 h} \int_{0}^{2 \pi} \Delta T(1+2 \cos \phi) \alpha \phi\right] \\
& y=a(1-\cos \phi) \\
& \ddot{x}=a \sin \phi \\
& \bar{T}=974-12.5 \cos \phi \\
& \Delta T=27
\end{aligned}
$$


ATOMICS INTERNATIONAL

NO. T RR 6270

A Division of North American Aviation, Inc

DATE Apr in 12, 1961

PAGE 13 OF

$$
\begin{aligned}
& x_{0}=\frac{D}{\pi a^{2}}(1+\nu) \alpha\left[\int_{0}^{2 \pi}(974-12.5 \cos \phi) \cos \phi \alpha \phi-\frac{a}{b} \int_{0}^{2 \pi} 27 \cos \phi \phi \phi\right] \\
& X_{0}=-\frac{12.5 D(1+\nu) \alpha}{a^{2}} \\
& Y_{0}=\frac{D}{\pi a^{2}}(1+\nu) \alpha\left[\int_{0}^{2 \pi}(974-12.5 \cos \phi) \sin \phi d \phi-\frac{a}{b} \int_{0}^{2 \pi} 27 \sin \phi \alpha \phi\right] \\
& Y_{0}=0 \\
& M_{0}=\frac{D}{\pi a}(1+\nu) \alpha\left[-\int_{0}^{2 \pi}(974-12.5 \cos \phi) \cos \phi \alpha \phi+\frac{a}{2 h} \int_{0}^{2 \pi} 27(1+2 \cos \phi) d \phi\right] \\
& M_{0}=\frac{D(1+\nu) \alpha}{a}\left[12.5+\frac{27 a}{h}\right] \\
& M_{\phi}=M_{0}+x_{0} y-Y_{0} x \\
& M_{\phi}=D(1+\nu) \alpha\left[\frac{12.5}{a}+\frac{27}{h}-\frac{12.5}{a}(1-\cos \phi)\right]
\end{aligned}
$$

$M_{\phi}$ is a maximum at $\phi=0$; therefore,

$$
M_{\phi_{\max }}=D(1+\nu) \alpha\left[\frac{22.5}{B}+\frac{2 \pi}{b}\right]
$$

Therefore,

$$
\begin{aligned}
\sigma_{\phi_{\max }} & =\frac{{ }^{6 \phi_{\max }}}{h^{2}}=\frac{12 \alpha}{2(1-2)}\left[\frac{12.5}{a}+\frac{27}{\mathrm{~h}}\right] \\
& =\frac{\left(23 \times 10^{6}\right)(0.010)\left(10 \times 10^{-6}\right)}{(2)(0.7)} \cdot\left[\frac{12.5}{.33}+\frac{27}{0.010}\right] \\
& =4,500 \mathrm{ps} 1 .
\end{aligned}
$$

$730-V-45$ (REV 5-59)

14 


\section{ATOMICS INTERNATIONAL}

A Division of North American Aviation, Inc.

NO. $\frac{\text { TDR } 6270}{\text { DARII } 12,1962}$
PATE $\frac{\text { ADE }}{14 \text { OF } 49}$

For the longltudinal analys 18, it will be assumed that it 18 sufficlently accurate to work with the mean temperatures of the cross section involved.

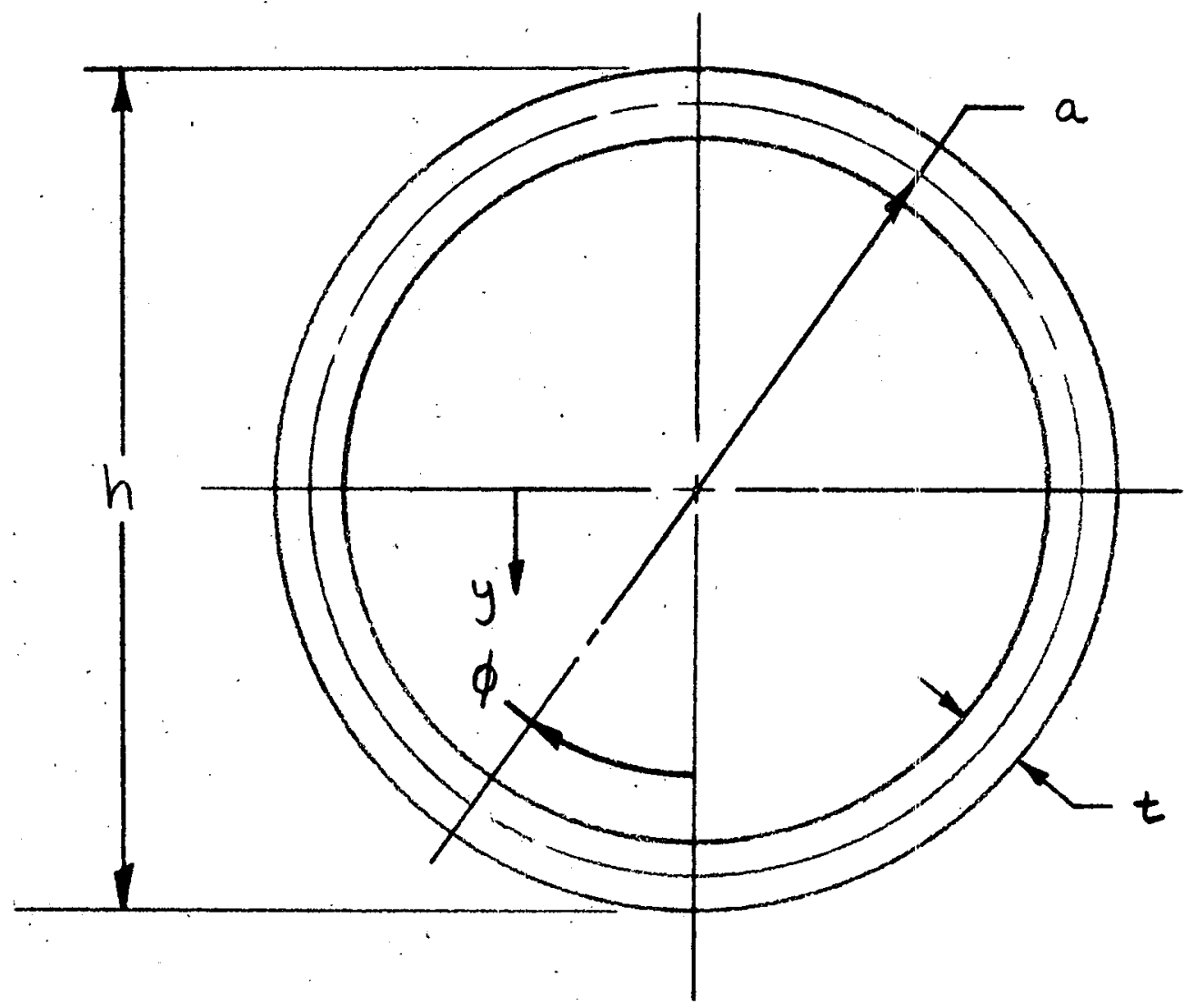

$T=974-12.5 \cos \phi$

$\bar{T}=\frac{1}{h} \int_{-h / 2}^{h / 2} T d y$

(Re1. 5)

$\overline{\mathrm{T}}=974 \mathrm{~T}$

$\Delta T=\frac{12}{h^{2}} \int_{-h / 2}^{h / 2} T y d y$

(Ref'. 5)

$\Delta T=25 T$ 


\section{ATOMICS INTERNATIONAL}

NiD.

TDR 6270

A Division of North American Aviation, Ine.

DATE Apr11 12, 1961

PAGE $15 \quad$ OF 49

The stress in the rod will be determined by assumlas the conservative system shown below.

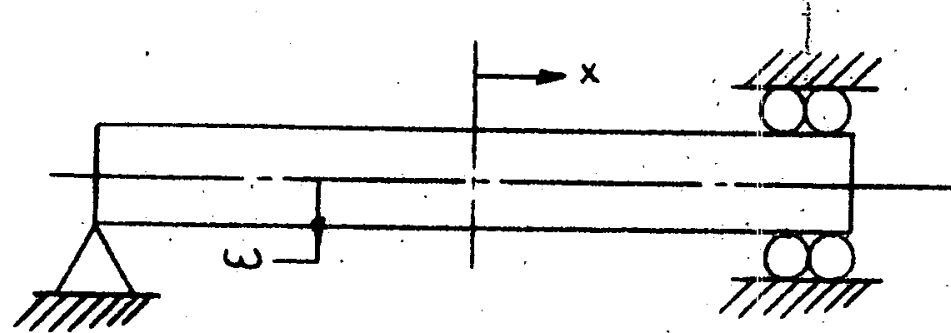

$-L$

$+L$

The general solution for deflection the above beam is,

$$
v=-\frac{\alpha}{h} \int_{0}^{x}\left[\int_{0}^{x} \Delta T d x\right] d x+\frac{c_{1} x^{3}}{6}+\frac{c_{2} x^{2}}{2}+c_{3} x+c_{4} \quad \text { (Ref. 5) }
$$

Where the C's depend on the boundary conditions.

at $x= \pm L, w=0$
at $x=-L ; \quad w=0=-\frac{\alpha}{h} \Delta T \frac{L^{2}}{2}-\frac{C_{1} L^{3}}{6}+\frac{C_{2} L^{2}}{2}-C_{3} L+C_{4}$

at $x=I ; \quad y=0=-\frac{\alpha}{h} \Delta T \frac{L^{2}}{2}+\frac{C_{1} L^{3}}{6}+\frac{C_{2} L^{2}}{2}+c_{3} L+c_{4}$

The moment, $M, 18$ defined as,

$$
M=-\operatorname{EI}\left(\frac{d^{2} w}{d x^{2}}+\frac{\alpha \Delta t}{h}\right)
$$

at $x=-I ; \quad M=0$ :

$$
M=0=-C_{1} L+C_{2}
$$




\section{ATOMICS INTERNATIONAL}

A Division of North American Aviation, Inc.

NO. $\operatorname{TDR} 6270$

DATE Apr11 12, 1961

PAGE 16 OF

at $x=+I ; \quad \frac{d w}{d x}=0$ :

$$
\frac{d w}{d x}=0=-\frac{\alpha}{h} \Delta \pi+\frac{c_{1} L^{2}}{2}+c_{2} L+c_{3}
$$

Adding Eq. (2) to Eq. (1),

$$
c_{2} I^{2}+2 c_{4}=\frac{\alpha}{h} \quad \Delta T^{2}
$$

Subtracting Eq. (3) from Eq. (4)

$$
\frac{C_{1} L^{2}}{2}+C_{1} L^{2}+C_{3}=\frac{\alpha}{h} \Delta T L
$$

or,

$$
\frac{3}{2} C_{1} L^{3}+C_{3} L=\frac{\alpha}{b} \Delta L^{2}
$$

From Equations (2) and (3)

$$
\frac{C_{1} L^{3}}{6}+\frac{c_{1} L^{3}}{2}+c_{3} L+c_{4}=\frac{\alpha}{h} \Delta T \frac{L^{2}}{2}
$$

or,

$$
\frac{2}{3} c_{1} I^{3}+c_{3} I+c_{4}=\frac{\alpha}{h} \Delta T \frac{L^{2}}{2}
$$

Subtract1ng Eq. (7) Prom Eq. (6)

$$
\begin{aligned}
& \frac{5}{6} c_{1} L^{3}-c_{4}=\frac{\alpha}{h} \Delta T \frac{L^{2}}{2} \\
& c_{4}=\frac{5}{6} c_{1} L^{3}-\frac{\alpha}{h} \Delta T \frac{L^{2}}{2}
\end{aligned}
$$

From Equations (5) and (3), and using the above relatinnship for $c_{4}$,

$$
C_{1} L^{3}+\frac{5}{3} \quad C_{1} L^{3}=\frac{2 \alpha \Delta T L^{2}}{h}
$$

or,

$$
c_{1}=\frac{3}{4} \alpha \frac{\Delta T}{h \mathrm{~T}}
$$



of 49

and,

$$
c_{2}=c_{1} I=\frac{3}{4} \alpha \frac{\Delta T}{h}
$$

How,

$$
\begin{aligned}
& M=-\left(c_{1} x+c_{2}\right) \\
& \frac{M}{I}=-E\left[\frac{3}{4} \alpha \frac{\Delta T}{h}\right]\left[\frac{x}{L}+1\right]
\end{aligned}
$$

At $x=I$ the moment equation ylelds:

$$
\frac{M}{I}=-E \alpha\left[\frac{3}{2} \frac{\Delta T}{h}\right]
$$

The stress is given by,

$$
\sigma_{x}=\frac{M y}{I}-E \alpha\left[T-\bar{T}-\Delta T \frac{y}{h}\right]
$$

Hote: The second term in the above equation 18 not exactly correct since these stresses do not fully develop at the ends; but, the equation as given w11 suffice 83 a first order approximation.

$$
\begin{aligned}
\sigma_{x} & =-E \alpha \frac{3}{2} \frac{\Delta T}{h} y-E \alpha\left[T-\bar{T}-\Delta T \frac{y}{h}\right] \\
& =-E \alpha\left[T-\bar{T}+\frac{\Delta T}{2} \frac{y}{h}\right]
\end{aligned}
$$

Substituting in values for $T, \bar{T}$, and $\Delta T$ given on pages 11 and 12 ,

$$
\sigma_{x}=-E \alpha\left[-12.5 \cos \phi+\frac{25}{2 h} y\right]
$$

When $\phi=0$ and $y=\frac{h}{2}$,

$$
\sigma_{x}=-\operatorname{B\alpha } \alpha\left[-12.5+\frac{12.5}{2}\right]=1,440 \mathrm{p} 81
$$

then $\phi=\pi$,

$$
\sigma_{x}=-\mathrm{E} \alpha\left[+12.5-\frac{12.5}{2}\right]=-1,440 \mathrm{ps} 1
$$


At $x=-I$,

$$
\begin{aligned}
& M=0 \\
& \sigma_{x}=-E \alpha\left[T-\bar{T}-\Delta T \frac{y}{h}\right]
\end{aligned}
$$

The note listed on Page 17 also applies to the above equation.

$$
\sigma_{x}=-E \alpha\left[-12.5 \cos \phi-25 \frac{y}{h}\right]
$$

When $\phi=0$ and $y=\frac{h}{2}$,

$$
\sigma_{x}=-E \alpha[-12.5-12.5]=5,750 \mathrm{po1}
$$

When $\phi=\pi$

$$
\sigma_{x}=-5,750 \mathrm{ps} 1
$$

Consldering the rod free the center deflection vould be given by:

$$
\delta=\frac{\alpha \Delta T l^{2}}{8 h}
$$

The center deflection of a beam subjected to equal and opposite end moments would be:

$$
\delta=\frac{M l^{2}}{\delta E I}
$$

Therefore the thermal moment is:

$$
\begin{aligned}
& \frac{M_{t} l^{2}}{d E I}=\frac{\alpha \Delta T l^{2}}{8 h} \\
& M_{t}=\frac{E \pi a^{3}}{2 a} \alpha \Delta T=E \alpha \frac{\Delta T}{2} \pi a^{2} t \\
& M_{t}=230 \times \frac{25}{2} \times \pi(.109)(.01) \\
& M_{t}=9.85 \mathrm{in}-1 b
\end{aligned}
$$


No. TPR 6270

To determine the reactions at the various fuel rod spacers, the thermal moment will be treated as an externally applied mainent and a continuous beam solution will be applied. Therefore we heve:

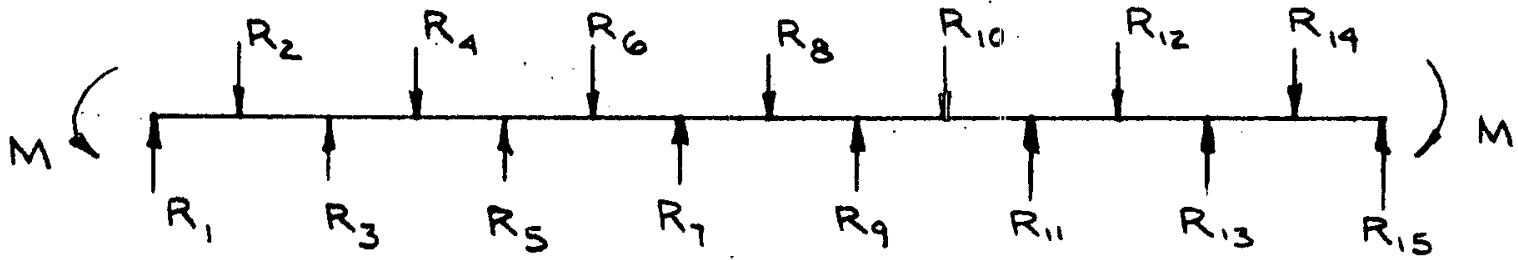

Slnce all the spans are equal, the continuous beam solution ylelds the following equations:

$$
\begin{aligned}
& M+4 M_{2}+M_{3}=0 \\
& M_{2}+4 M_{3}+M_{4}=0 \\
& M_{3}+4 M_{4}+M_{5}=0 \\
& M_{4}+4 M_{5}+M_{6}=0 \\
& M_{5}+4 M_{6}+M_{7}=0 \\
& M_{6}+4 M_{7}+M_{8}=0 \\
& M_{7}+4 M_{8}+M_{9}=0 \\
& \text { etc: }
\end{aligned}
$$

From symmetry,

$$
\begin{aligned}
& x_{1}=M_{9} \\
& x_{2}=M_{14} \\
& \text { etc: }
\end{aligned}
$$


Therefore,

$$
\begin{aligned}
& M_{7}=-2 M_{8} \\
& M_{6}=7 M_{8} \\
& M_{5}=-28 M_{8}+2 M_{8}=-26 M_{8} \\
& M_{4}=97 M_{8} \\
& M_{3}=-362 M_{8} \\
& M_{2}=1351 M_{8} \\
& M=-5042 M_{8}
\end{aligned}
$$

Solution of the above equations ylelde,

$$
\begin{aligned}
& M_{8}=-1.955 \times 10^{-3} \mathrm{ln}-1 \mathrm{~b} \\
& M_{7}=M_{9}=3.91 \times 10^{-3} \mathrm{ln}-1 \mathrm{~b} \\
& M_{6}=M_{10}=-13.7 \times 10^{-3} \mathrm{ln}-1 \mathrm{~b} \\
& M_{5}=M_{11}=50.9 \times 10^{-3} \mathrm{ln}-1 \mathrm{~b} \\
& M_{4}=M_{12}=-189.5 \times 10^{-3} \mathrm{ln}-1 \mathrm{~b} \\
& M_{3}=M_{13}=708 \times 10^{-3} \mathrm{ln}-1 \mathrm{~b} \\
& M_{2}=M_{14}=-2642 \times 10^{-3} \mathrm{ln}-1 \mathrm{~b}
\end{aligned}
$$

Solution for the loads yields,

$$
\begin{aligned}
& R_{1}=R_{15}=1.04 \mathrm{Ib} \\
& R_{2}=R_{14}=1.32 \mathrm{Ib} \\
& R_{3}=R_{13}=0.354 \mathrm{Ib} \\
& R_{4}=R_{12}=0.0835 \mathrm{lb} \\
& R_{5}=R_{11}=0.0103 \mathrm{lb} \\
& R_{6}=R_{10}=0.00802 \mathrm{lb} \\
& R_{7}=R_{9}=0.00279 \mathrm{lb} \\
& R_{8}=0.008861 \mathrm{~b}
\end{aligned}
$$


If spacers number (2) and (14) have slop or yleld sich that they carry no load, the following condition will oceur.

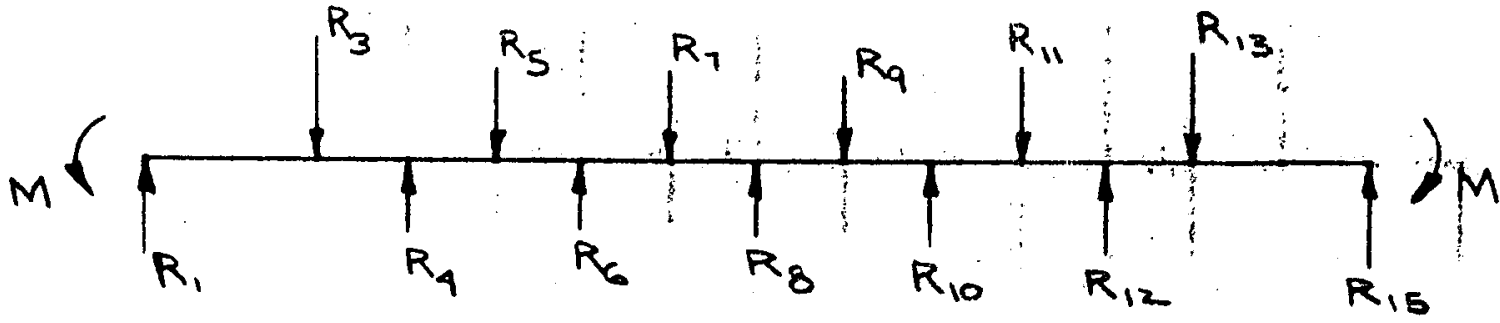

The continuous beam solution in this case becomes,

$$
\begin{aligned}
& M+2 M_{3}+M_{4}=0 \\
& M_{3}+4 M_{4}+M_{5}=0 \\
& M_{4}+4 M_{5}+M_{6}=0 \\
& M_{5}+4 M_{6}+M_{7}=0 \\
& M_{6}+4 M_{7}+M_{8}=0 \\
& M_{7}+4 M_{8}+M_{9}=0 \\
& \text { etc. }
\end{aligned}
$$

Prom symetry: $M_{7}=K_{9}$, etc. Therefore,

$$
\begin{aligned}
& M_{7}=-2 M_{8} \\
& M_{6}=7 M_{8} \\
& M_{5}=-26 M_{8} \\
& M_{4}=97 M_{8} \\
& M_{3}=-362 M_{8} \\
& M=2075 M_{8}
\end{aligned}
$$


Solution of the above equations yields,

$$
\begin{aligned}
& M_{8}=4.75 \times 10^{-3} \mathrm{1n}-1 \mathrm{~b} \\
& M_{7}=M_{9}=-9.5 \times 10^{-3} \mathrm{In}-1 \mathrm{~b} \\
& M_{6}=M_{10}=33.25 \times 10^{-3} \mathrm{In}-1 \mathrm{~b} \\
& M_{5}=M_{11}=123.5 \times 10^{-3} \mathrm{In}-1 \mathrm{~b} \\
& M_{4}=M_{12}=461 \times 10^{-3} \mathrm{In}-1 \mathrm{~b} \\
& M_{3}=M_{13}=-1720 \times 10^{-3} \mathrm{In}-1 \mathrm{~b}
\end{aligned}
$$

Solving for the reactions,

$$
\begin{aligned}
& R_{1}=R_{15}=0.482 \mathrm{lb} \\
& R_{3}=R_{13}=0.664 \mathrm{lb} \\
& R_{4}=R_{12}=0.2325 \mathrm{Ib} \\
& R_{5}=R_{11}=0.0644 \mathrm{Ib} \\
& R_{6}=R_{10}=0.01535 \mathrm{Ib} \\
& R_{7}=R_{9}=0.0069 \mathrm{Ib} \\
& R_{8}=0.0109 \mathrm{lb}
\end{aligned}
$$

It is seen from this that, if the number (2) and number (14) spacers y1eld, the rest of the spacers will pick up the load. However, the load carried by each spacer will be lover than the maxtmum loadi ( $R_{2}$ and $R_{14}$ ) occurring In the first case.

The maximum fuel rod bow 111 be found for the above two cases. For the f1rat case, with all spacers acting, we have in the firsti two spans the situation show below.

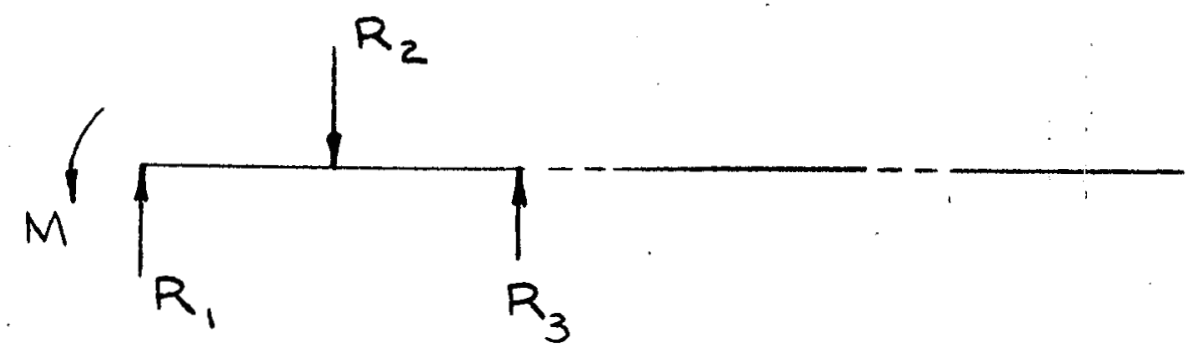


By superposition this can be shown as,

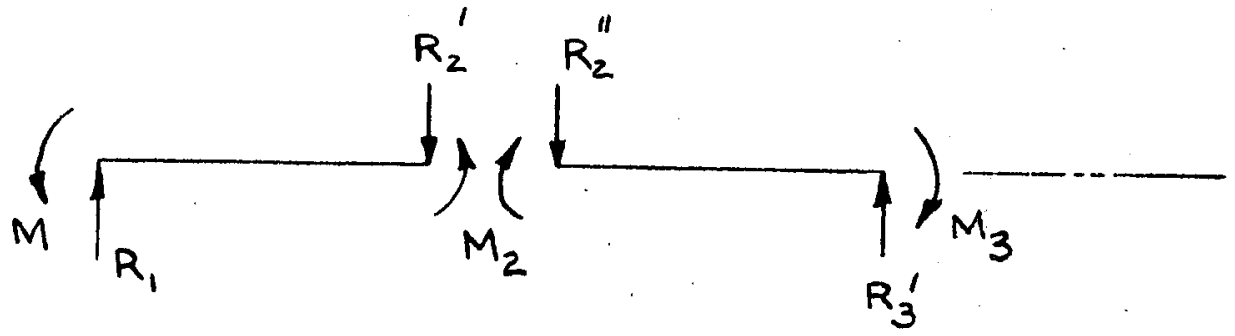

Where:

$$
R_{2}^{\prime}+R_{2}^{\prime \prime}=R_{2}
$$

The maximum bow will occur in the end spans. By siperposition it can be show that the deflection of the ond span is the comblnation of the two situations show below:
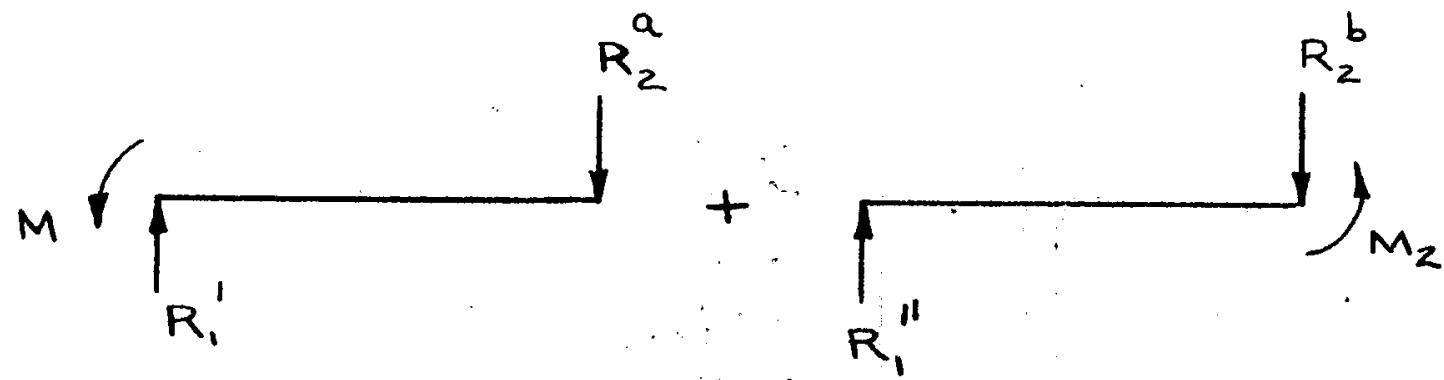

Where:

$$
R_{1}^{\prime \prime}+R_{1}^{\prime}=R_{1}
$$

and

$$
R_{2}^{a}+R_{2}^{b}=R_{2}
$$


ATOMICS INTERNATIONAL

A Division of North American Aviation, Inc.

NO. TR 6270

DATE Apr 1] 12,1961

PAGE 24 _OF 49

The deflection for the two beams combined would be:

$$
\delta=\frac{M x}{6 l E I}(l-x)(2 l-x)-\frac{M_{2} l x}{6 I I}\left(1-\frac{x^{2}}{l^{2}}\right) \text { (Ref. 2) }
$$

At the point of maximum deflection:

$$
\begin{aligned}
& \frac{d \delta}{d x}=0=\frac{d}{d x}\left[M\left(2 l^{2} x-3 l x^{2}+x^{3}\right)-M_{2}\left(x l^{2}-x^{3}\right)\right] \\
& 0=M\left(2 l^{2}-6 l x+3 x^{2}\right)-M_{2}\left(l^{2}-3 x^{2}\right) \\
& \text { Since } M_{2}=0.2682 M \\
& 0=2 l^{2}-6 l x+3 x^{2}-0.2682 l^{2}+0.805 x^{2}
\end{aligned}
$$

or,

$$
0=0.455 l^{2}-1.575 l x+x^{2}
$$

Solution of the above yields,

$$
x=0.3815 l
$$

At $x=0.3815 l$,

$$
\begin{aligned}
& \delta=\frac{y}{6 l \mathrm{EI}}\left[2 \ell^{2} x-3 \ell x^{2}+x^{3}-0.2682 x l^{2}+0.2682 \mathrm{x}^{3}\right] \\
& \delta=\frac{0.295 \mathrm{M} \ell^{2}}{6 \mathrm{EI}}
\end{aligned}
$$

At $1000 \mathrm{~F}$,

$$
\begin{aligned}
& E=21 \times 10^{6} \mathrm{ps} \\
& I=1.13 \times 10^{-3} \mathrm{1n}^{4} \\
& \ell=12 \mathrm{1n} .
\end{aligned}
$$

Therefore,

$$
\begin{aligned}
& \delta=\frac{0.295 \times 9.85 \times 1.44}{6 \times 21 \times 1.13 \times 10^{3}} \times 10^{2} \\
& \delta=2.94 \times 10^{-3} \mathrm{in} .
\end{aligned}
$$

$730-V-45$ (REV 5-59) 
NO. TOR 6270

ATOMICS INTERNATIONAL

DATE - Apr 11 12,1961

A Division of North American Aviation, lIne.

PAGE

OF

4 .

For the case when spacers number (2) and (14) yield, the deflection equation would be:

$$
\delta=\frac{M\left(2 \ell^{2} x-3 l x^{2}+x^{3}\right)}{6 l E I}-\frac{M_{3}\left(x l^{2}-x^{3}\right)}{6 l \text { BI }}
$$

The point of maximum deflection is found in the same manner as above.

$$
\frac{d \delta}{d x}=0=M\left(2 l^{2}-6 l x+3 x^{2}\right)-M\left(l^{2}-3 x^{2}\right)
$$

where,

$$
M_{3}=0.1748 \mathrm{M}
$$

Therefore $\delta$ is a maximum at,

$$
\begin{aligned}
& 0=2 l^{2}-6 l x+3 x^{2}-0.1748 l^{2}+0.5244 x^{2} \\
& 0=3.5244 x^{2}-6 l x+1.8252 l^{2} \\
& x=0.397 l
\end{aligned}
$$

Solution for $\delta_{\max }$ follows:

$$
\begin{aligned}
& \delta=\frac{M}{6 \ell \mathrm{EI}}\left(2 \ell^{2} x-3 l x^{2}+x^{3}-0.1748 x l^{2}+0.1748 x^{3}\right) \\
& \delta=0.3251 \frac{M l^{2}}{6 \mathrm{EI}}
\end{aligned}
$$

For this case,

$$
\begin{aligned}
& E=21 \times 10^{6} \mathrm{ps1} \\
& I=1.13 \times 10^{-3} \\
& \ell=24 \mathrm{in} .
\end{aligned}
$$

Then,

$$
\begin{aligned}
& \delta=\frac{0.3251 \times 9.85 \times 5.76 \times 10^{2}}{6 \times 21 \times 1.13 \times 10^{3}} \\
& \delta=1.295 \times 10^{-2} \mathrm{ln} .
\end{aligned}
$$

$730-V-45$ (REV 5-59) 
The maximum deflections for each case are small and should cause no trouble.

\section{Critical Pressure:}

The critical pressure for the fuel rod at $1000 \mathrm{~F}$ ia given by:

$$
\begin{aligned}
& P=\frac{1}{4} \frac{E}{\left(1-V^{2}\right)} \frac{t^{3}}{R^{3}} \\
& P=\frac{1}{4} \frac{21 \times 10^{6}}{(0.91)} \times \frac{10^{-6}}{0.036} \\
& P=160 \mathrm{ps} 1
\end{aligned}
$$

The eritical pressure for the center fuel rod at $1000 \mathrm{~F}$ 1s:

$$
\begin{aligned}
& P=\frac{1}{4} \times \frac{21 \times 10^{6}}{0.91} \frac{8 \times 10^{-6}}{0.0393} \\
& P=1175 \mathrm{ps1}
\end{aligned}
$$

The above solutions do not consider effects of out-of-roundness in the tubing; but, th1s should not be a problem with the high safety margins predicted (1.e. external pressures should be less than 30 ps1). 


\section{ATOMICS INTERNATIONAL}

A Division of North American Aviation, Ins.

NO). TDR 6270

DATE Apr11 12, 1961

PAGE 27 OF

\section{Support Plate}

The support plate to be analyzed 18 show below. There are three such sections velded together.
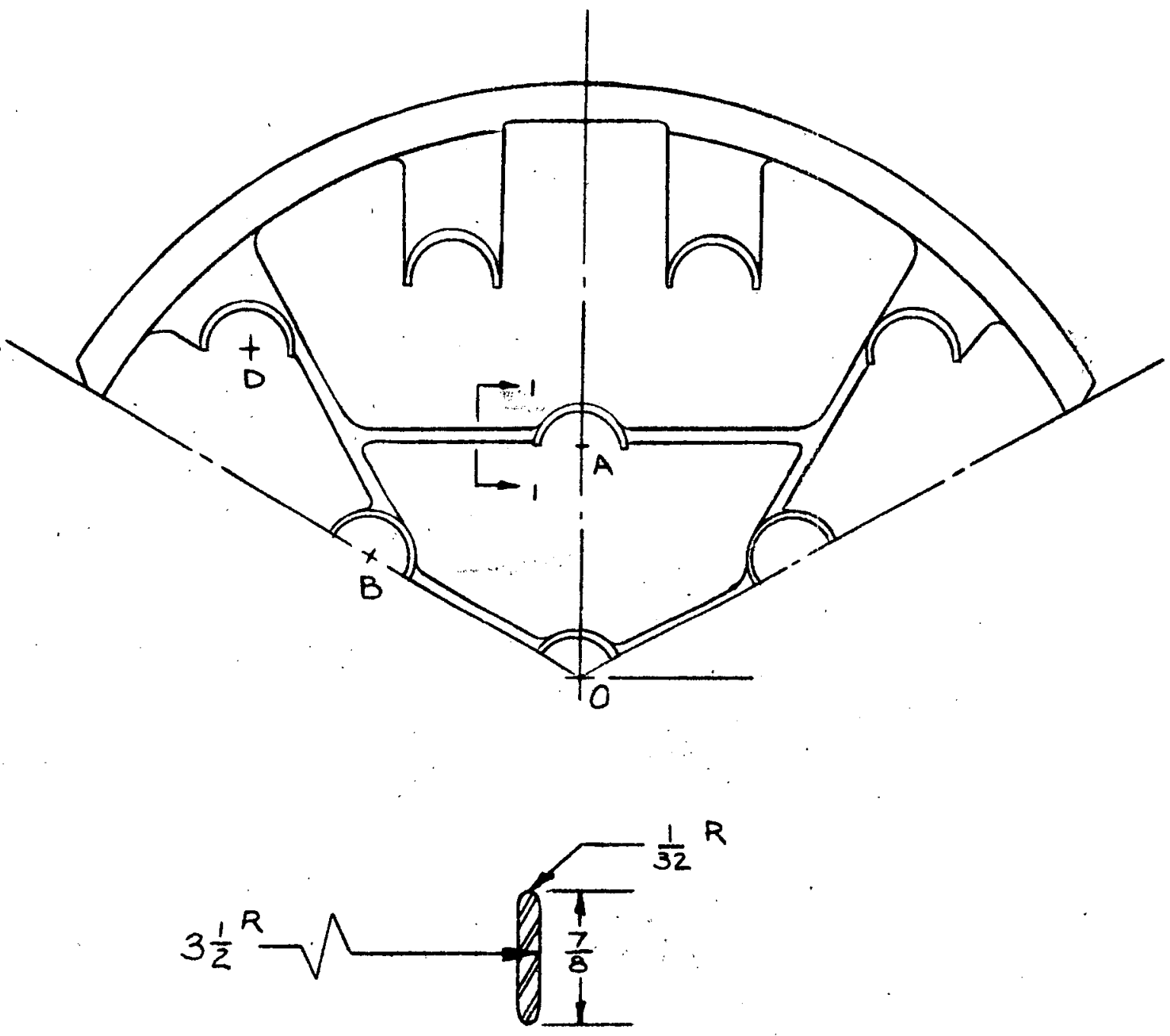

Section 1-1 


\section{ATOMICS INTERNATIONAL}

A Division of North Americon Aviation, Ine.

NO.

TDR 6270

DATE April 12, 1961

PAGE 28 OF 49

The center section of the support show below w1ll be considered as a simply supported beam subjected to a center loading equal to the weight of one fuel rod.

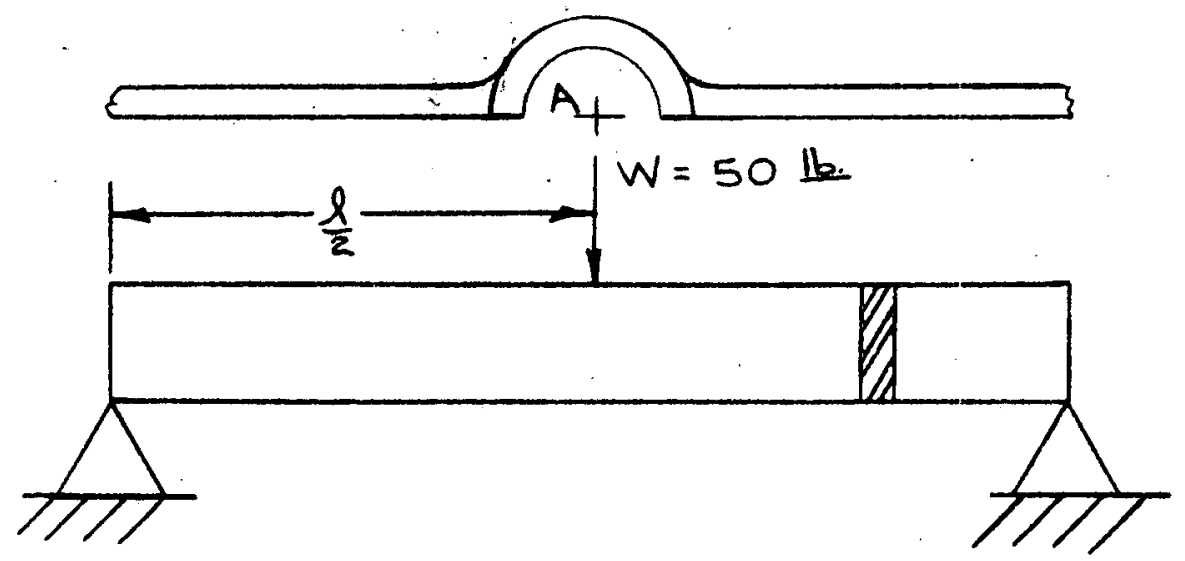

The cross section will be taken as a rectangular cross section $3 / 32$ inches thick by $7 / 8$ inches high.

$$
z=\frac{b h^{2}}{6}=\frac{0.093}{6} \times(0.875)^{2}=0.01186 \mathrm{in}^{3}
$$

The bending stress is given by

$$
\sigma=\frac{M}{\mathbf{Z}}
$$

where: $M=\frac{1}{4} \quad W l=\frac{1}{4} \times 50 \times 2 \times .694=17.35 \mathrm{ln}-1 \mathrm{~b}$

$$
\sigma=1,460 \mathrm{ps} 1
$$


ATOMICS INTERNATIONAL

A Division of North American Aviation, line.

$$
\begin{aligned}
& \text { NO. ToR } 6270 \\
& \text { DATE Apr11 12, } 1961 \\
& \text { PAGE } 29 \text { OF } \\
& 49
\end{aligned}
$$

The next section considered is that shown below. For this analysis the following loads wi ll be assumed acting at the point of concern.

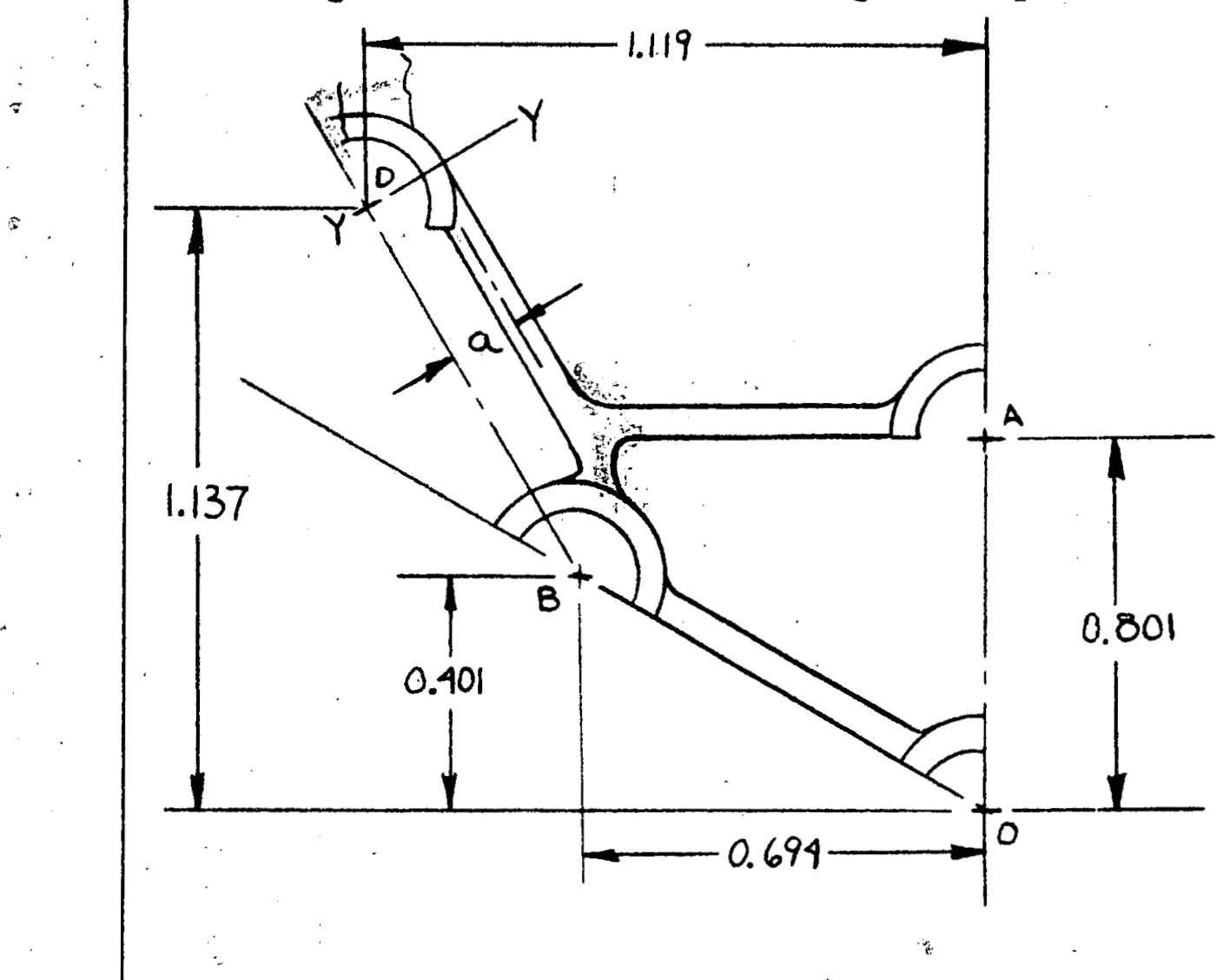

At $B, P_{B}=\frac{1}{2} W$

At $0, P_{0}=\frac{1}{6} W$

At $A, P_{A}=\frac{1}{2}$

At $D, P_{D}=W$

$a=0.250-\frac{.093}{2}=.203^{\prime \prime}$

$730-V-45$ (REV . 5-59)

$05 ? \quad 30$ 
ATOMICS INTERNATIONAL

NO. TR 6270

DATE ADE11 12, 1961

- A Division of North American Aviation, Inc.

PAGE 30

OF

49

The distances involved from point $B$ to the $Y-Y$ axis are:

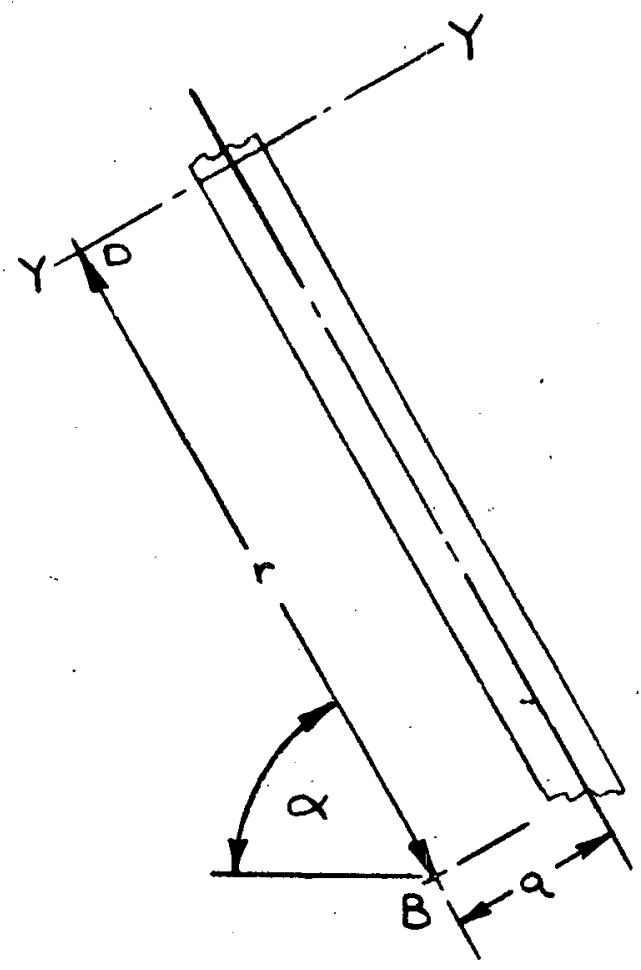

$a=.203^{\prime \prime}$

$\tan \alpha=\frac{1.137-.401}{1.119-.694}$

$\alpha=60^{\circ}$

$r=0.85$ inches

$730-V-45(R E V 5-59)$

$05 ? 31$ 


\section{ATOMICS INTERNATIONAL}

NO. TDR 6270

A Division of North American Aviation, Inc.

DATE Apr11 12, 1961

PAGE 32 OF 49

The distances from point $O$ to $Y-Y$ axis are shown below.

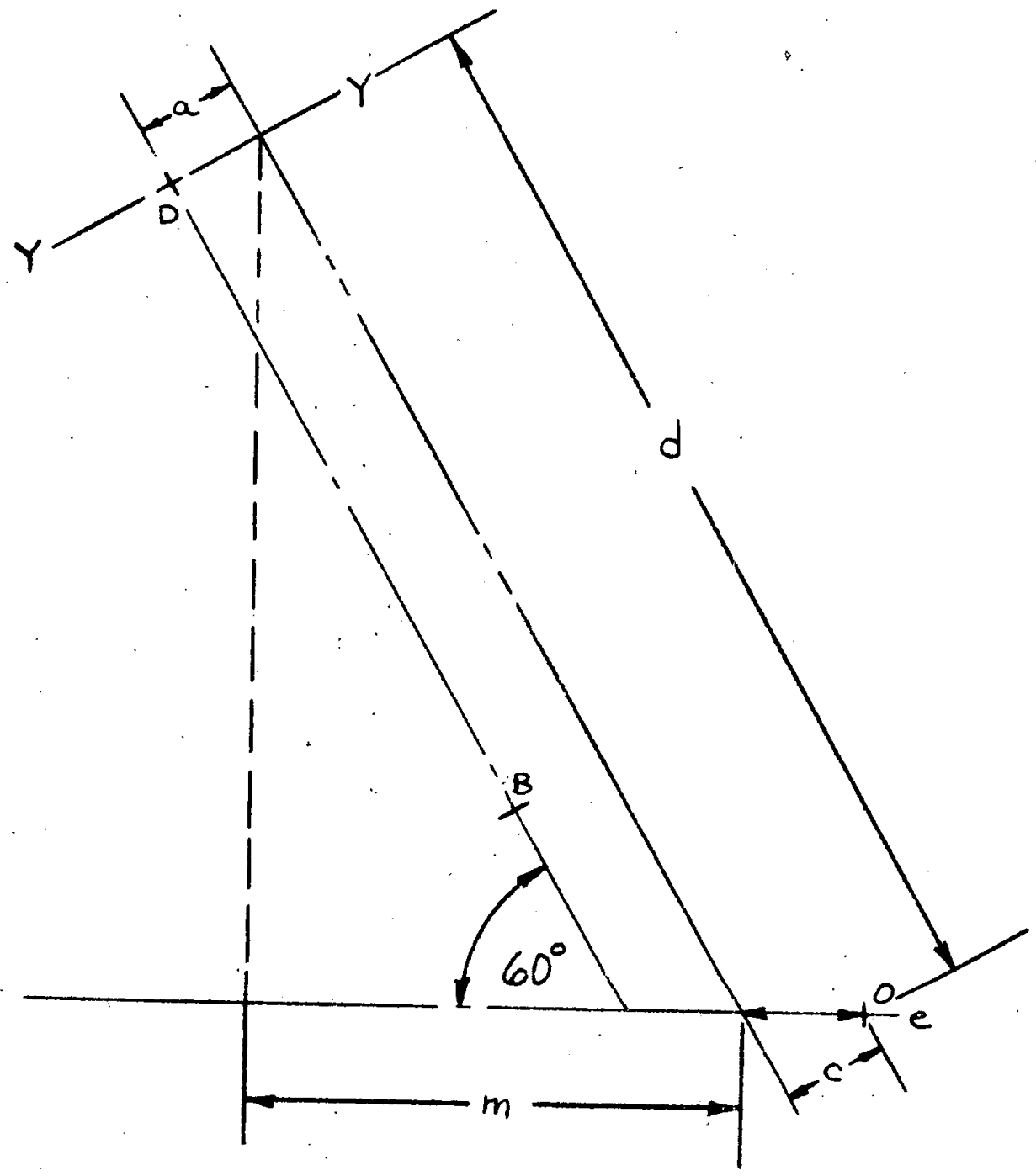

$m=\frac{1.137+a \sin 30^{\circ}}{\tan 60^{\circ}}=0.714$ in

$e=1.119-m-a \cos 30^{\circ}=0.231$ in.

$c=0.2 \mathrm{ln}$.

$\mathrm{d}=1.544 \mathrm{in}$. 
From point $A$ to the $Y-Y$ axis the distances are:

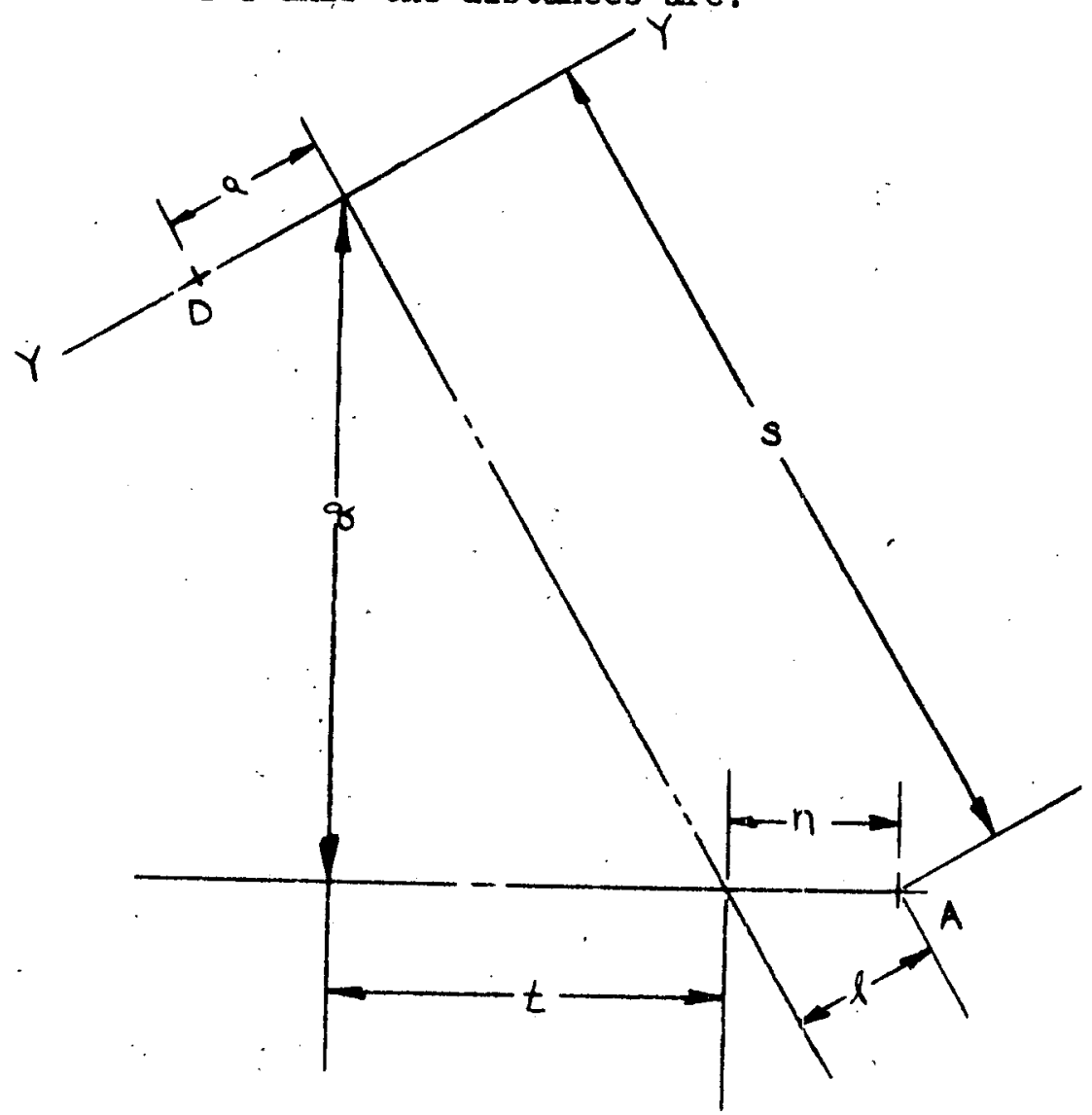

$$
\begin{aligned}
& q=1.2385-0.801=0.4375 \mathrm{in} . \\
& t=\frac{q}{\tan 60^{\circ}}=0.252 \mathrm{1n} . \\
& n=\left(1.119-\mathbf{a c o s} 30^{\circ}\right)-t \\
& n=0.691 \mathrm{in} . \\
& l=0.6 \mathrm{in} . \\
& \mathbf{n}=0.85 \mathrm{in} .
\end{aligned}
$$


The torsional moment acting is now determined from:

$$
\begin{aligned}
M_{T} & =P_{D} a+P_{B} a-P_{A}-P_{O} c \\
& =W\left[\begin{array}{ll}
a+\frac{1}{2} a
\end{array}\right]-W\left[\frac{1}{2} l+\frac{1}{6} c\right] \\
& =W\left[\frac{3}{2} a-\frac{\ell}{2}-\frac{c}{6}\right] \\
H_{T} & =-0.0288 \mathrm{~W}=-1.44 \text { 1n-1b }
\end{aligned}
$$

The shearing stress in a rectangular cross-section is given by:

$$
\tau=\frac{M_{t}}{\alpha b b^{2}}
$$

where

$$
\begin{aligned}
& \mathrm{b}=\text { long side dimension }=0.875 \mathrm{in} . \\
& \mathrm{h}=\text { short side dimension }=0.093 \mathrm{in} . \\
& \alpha=\text { factor depending on rat10 of } \mathrm{b} / \mathrm{h}
\end{aligned}
$$

for $b / h=9.4$

$$
\alpha=0.311
$$

The torslonal stress is,

$$
\tau=\frac{1.44}{.311 \times .875 \times .093^{2}}=615 \mathrm{ps} 1
$$

The bending moment at the section of concern is:

$$
\begin{aligned}
M & =P_{B} r+P_{0} d+P_{A} s \\
& =W\left[\frac{r}{2}+\frac{d}{6}+\frac{s}{2}\right] \\
M & =55.41 \mathrm{n}-1 b \\
\nabla & =\frac{M}{Z}=4,670 \mathrm{psi}
\end{aligned}
$$

The above determination of $\tau$ and $\sigma$ is conservative to some extent since the effects of continuous members were neglected. 
Pressure Build-up in Rod

It will be assumed that the fuel element pressure can build up to a value h1gh enough to cause a stress of 17,000 psi (yield stress for Type $304 \mathrm{s.S}$. at $1000 \mathrm{~F}$ ) before any creep will occur. The value of this pressure 18,

$$
\begin{aligned}
& \sigma=\frac{P R}{t} \\
& P=\frac{17000}{33}=515 \mathrm{ps} 1
\end{aligned}
$$

The elastic radial strain is then.

$$
\epsilon_{R}=\frac{\pi}{E}\left(1-\frac{2}{2}\right)
$$

where: $E=$ Youngs Modulus, $21 \times 10^{6} \mathrm{ps} 1$ (1000 F

$$
\begin{aligned}
& \nu=\text { Polsson's rat1o, } 0.3 \\
& \epsilon_{R}=0.000689
\end{aligned}
$$

Using a yleld stress of 17,000 ps1 ( 0.2 percent off'set) the strain at the yleld point for Type 304 stifnless steel at $1000 \mathrm{~F} \mathrm{18}$,

$$
\epsilon_{\mathrm{E}}=(0.2+0.0689)=0.2689 \text { percent }
$$

The pressure build-up within the rod using an inflexible cladding is,

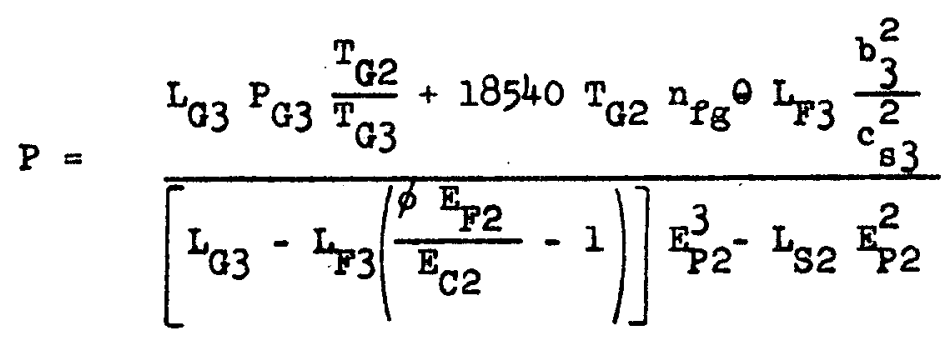

The above nomenclature is defined in Ref. 7 .

It is assumed that: (1) the loading temperature is $300 \mathrm{~F}$; (2) the gas temperature $18945 \mathrm{~F}$ in the hot 1rradiated condition; and, (3) the fraction of P1ssion gases produced, and the lineal irradiation growth factor for the fuel are linearly related to time in the core. 
Using the values given in ReP. 7, the equation can be written as,

$$
P=\frac{372.5+486.8 m / 48}{157.7-146.8 \phi^{3}+2 \phi}
$$

Where: $\phi=(1+\Phi)^{1 / 3}$; lineal 1rradiation growth factor for fuel materlal.

$$
\begin{aligned}
& \Phi=\text { Irradiation growth factor }=0.15 \\
& m=\text { months of Irradiation } \\
& 486.8=\text { P1ssion gas release term after } 48 \text { months in core }
\end{aligned}
$$

From assumption (3),

$$
\phi=1+k_{1} \frac{m}{48}
$$

When $\mathrm{m}=48, \phi=(1.15)^{1 / 3}$

(Ref. 8)

Equating the above two expressions,

$$
1.05=1+K_{1}
$$

Therefore,

$$
\mathrm{K}_{1}=0.05
$$

The equation defining pressure build-up in the rod is now written as:

$$
P=\frac{372.5+10.15 \mathrm{~m}}{12.9-1.66 \times 10^{-7} \mathrm{~m}^{3}-4.77 \times 10^{-4} \mathrm{~m}^{2}-0.457 \mathrm{~m}}
$$

Since the above pressure equation was obtalned using perfect gas laws; the avallable gas volume $\left(v_{g}\right)$ is proportional to the denominator of the equation above $\left(1\right.$ e.e. $\left.P=\frac{n R T}{V}\right)$.

Therefore,

$$
v_{g}=k_{2}\left[12.9-1.66 \times 10^{-7} \mathrm{~m}^{3}-4.77 \times 10^{-4} \mathrm{~m}^{2}-0.457 \mathrm{~m}\right]
$$

when, $m=0, V=4.03 \mathrm{in}^{3}$

Hence,

$$
k_{2}=\frac{4.03}{12.9}
$$

and

$$
V_{g}=\frac{4.03}{12.9}\left[12.9-1.66 \times 10^{-7} \mathrm{~m}^{3}-4.77 \times 10^{-4} \mathrm{~m}^{2}-0.457 \mathrm{~m}\right]
$$




\section{ATOMICS INTERNATIONAL}

A Division of North American Aviation, Inc.

Assuming that only radial growth affects the volumetric change.

$$
\begin{aligned}
& \left.\Delta V=\frac{d V}{d R} \Delta R=2 \pi R^{2} L \mid \frac{\Delta R}{R}\right) \\
& \Delta V=2 \pi R^{2} L \epsilon_{R}
\end{aligned}
$$

For a pressure of $515 \mathrm{ps} 1$ the change in volume due to straining the cladding is,

$$
\begin{aligned}
& \Delta v_{P}=2 \pi R^{2} L\left(0.2689 \times 10^{-2}\right) \\
& \Delta v_{P}=2 \pi(0.33)^{2}(180)\left(0.2689 \times 10^{-2}\right) \\
& \Delta v_{P}=0.3321 \mathrm{n.}
\end{aligned}
$$

The total gas rolume is equal to,

$$
\mathrm{v}_{\mathrm{T}}=\mathrm{v}_{\mathrm{g}}+\Delta \mathrm{v}_{\mathrm{P}}
$$

The total gas volume is also given by the perfect gas law. Hence at $515 \mathrm{ps} 1$, and $950 \cdot \mathrm{F}$

$$
\begin{aligned}
V_{T} & =N_{T} \frac{R T}{P} \\
& =N_{T} \frac{18540 \times 1410}{515+13.7}
\end{aligned}
$$

The total number of moles of gas is given by Ref. 7 as:

$$
N_{T}=N_{H e}+N_{P g}=4.486 \times 10^{-6}+5.83 \times 10^{-6}
$$

Since the fission gases are assumed linearly related to time, this can be written as,

$$
\begin{aligned}
& N_{T}=4.486 \times 10^{-6}+5.83 \times 10^{-6} \mathrm{~m} / 48 \\
& N_{T}=4.486 \times 10^{-6}+0.1212 \times 10^{-6} \mathrm{~m}
\end{aligned}
$$

and hence,

$$
\begin{aligned}
& V_{T}=(4.486+0.121201 .854 \times 14.1 \\
& V_{T}=0.228+0.00616 m
\end{aligned}
$$



OF

Equating the two expressions for the total volume, the time to reach 515 psi can be found,

$$
\begin{aligned}
0.228+6.16 \times 10^{-3} \mathrm{~m}= & 4.03-0.518 \times 10^{-7} \mathrm{~m}^{3}-1.49 \times 10^{-4} \mathrm{~m}^{2} \\
& -1.429 \times 10^{-1} \mathrm{~m}+0.332
\end{aligned}
$$

Solving graphically,

(see Appendix B)

$$
m=27 \text { months }
$$

During the Inftial perfod of 27 months; creep was assumed to be negligible and vas neglected in the calculations. However, after reaching 515 psi, for any period of time thereafter creep will be taken into account.

From the stress vs creep rate curve for 304 stainless-steel at $1000 \mathrm{~F}$. (Append1X B)

$$
\sigma=2.35 \times 10^{-4} \mathrm{e}+1.661 \times 10^{4}
$$

where: $e=$ creep rate in percent per month

The change in volume due to creep 1s:

$$
\Delta v_{\theta}=2 \pi R^{2} L_{e}\left|\frac{\Delta R}{R}\right|_{e}
$$

and:

$$
\left|\frac{\Delta R}{R}\right|_{e}=\frac{m_{1}^{e}}{100}
$$

Where $m_{1}=$ months $\left(m_{1}=m-27\right)$

Since:

$$
\begin{aligned}
& \nabla=\frac{P R}{t} \\
& P=\frac{t}{R}\left[2.35 \times 10^{4} \mathrm{e}+1.661 \times 10^{4}\right] \\
& \frac{P R}{t}-1.661 \times 10^{4}=2.35 \times 10^{4} \mathrm{e} \\
& \frac{R}{t}=\frac{0.33}{0.01}=33
\end{aligned}
$$




\section{ATOMICS INTERNATIONAL}

A Division of North American Aviation, Inc.

DATE Apr11 12, 1961

PAGE 38 OF 49

Therefore:

$$
\begin{aligned}
& e=\left[\frac{33 P-1.661 \times 10^{4}}{2.35 \times 10^{4}}\right] \\
& \frac{m_{1}}{100}=\frac{m_{1}\left[33 P-1.661 \times 10^{4}\right]}{2.35 \times 10^{6}}
\end{aligned}
$$

and the creep volumetric change becomes

$$
\Delta v_{e}=2 \pi R^{2} L_{e} m_{1} \frac{\left[33 P-1.661 \times 10^{4}\right]}{2.35 \times 10^{6}}
$$

Now the upper 8 feet of clading is at $950 \mathrm{~F}$ and is the creep length assumed. Evaluating the above for:

$$
\begin{aligned}
& \mathrm{R}=0.33 \mathrm{in} . \\
& \mathrm{L}_{\mathrm{e}}=96 \mathrm{in} . \\
& \Delta \mathrm{V}_{e}=\left[9.2 \mathrm{P} \times 10^{-4}-4640 \times 10^{-4}\right] \mathrm{m}_{1}
\end{aligned}
$$

Now assuming that the elastic change in rolume remains unchanged.

$$
\Delta v_{P}=0.332 \text { in. }{ }^{3}
$$

The third component of the total gas volume vas the 1rradiation gas volume which was shown to be:

$$
v_{g}=\frac{4.03}{12.9}\left[12.9-1.66 \times 10^{-7} \mathrm{~m}^{3}-4.77 \times 10^{-4} \mathrm{~m}^{2}-0.457 \mathrm{~m}\right]
$$

By substitution of $m=m_{1}+27$. Into the above frradiation gas volume becomes:

$$
v_{g}=\frac{4.03}{12.9}\left[0.209-1.66 \times 10^{-7} m_{1}^{3}-4.9045 \times 10^{-4} m_{1}^{2}-0.4831 m_{1}\right]
$$

The total volume is then:

$$
\begin{aligned}
v_{T}= & v_{B}+\Delta v_{P}+\Delta v_{e} \\
v_{T}= & {\left[9.2 \times 10^{-4} P-4640 \times 10^{-4}\right] m_{1}+0.332+\frac{4.03}{12.9}[0.209} \\
& \left.-1.66 \times 10^{-7}-4.9045 \times 10^{-4}-0.4831 \mathrm{~m}_{1}\right]
\end{aligned}
$$




\section{ATOMICS INTERNATIONAL}

A Division of North American Aviation, Inc.

NO. TDR 6270

DATE Apr11 12, 1961

PAGE 39 OF 49

By making use of the gas law again

$$
\begin{aligned}
& V_{T}=N_{T} \frac{R T}{P} \\
& V_{T}=\left[4.486+0.1212\left(m_{1}+27\right)\right] \quad \frac{1.854 \times 14.1}{P}
\end{aligned}
$$

Equating the two expressions yields:

$$
\begin{aligned}
& \mathrm{P}^{2}\left[9.2 \times 10^{-4} \mathrm{~m}_{1}\right]-\mathrm{P}\left[0.518 \times 10^{-7} \mathrm{~m}_{1}^{3}+1.53 \times 10^{-4} \mathrm{~m}_{1}^{2}\right. \\
& \left.+0.615 \mathrm{~m}_{1}-0.3973\right]-[203.1+3.17 \mathrm{~m}]=0
\end{aligned}
$$

The solution of this equation 1 s plotted in Appendix B along with the total strain associated wh each pressure. 


\section{REFERENCES}

1. IOL, J. Susnir to W. T. Morgan, "Insertion of Cold fuel Element into Sod1um Pool at $600 \mathrm{~F}$;" Pebruary 8, 1961.

2. Timoshenko and MacCullough, Elements of Strength of Mater1als, D. Van Nostrand Co., Inc., Third Edition.

3. Roark, R. J., Formulas for Stress and Strain, McGraw-H1ll Book Co., Inc, Th1rd Edition, 1959.

4. Sletten, H. I., Personal Comminication.

5. Pelnado, C. 0., Lecture Notes on, "Elast1c Thermal Stress and Deformation."

6. Goodier, J. H., "Thermal Stress in Long Cylindrical Shells Due to Temperature Varlation Round the C1rcumference, and through the Wall," Canadian Journal of Research; Apr11, 1937.

7. Sletten, H. L., TDR 3889 Addendum, "HRPF - Pressure Butldup in the 19-rod, U-10 w/O Mo Fuel Element," March 30, 1960.

8. IOL, Schall to Mahlmelster; July $7,1960$. 


\section{ATOMICS INTERNATIONAL}

A Division of North Americon Aviation, Inc.

\section{APPENDIX A}

Properties of Spacer Rib Section

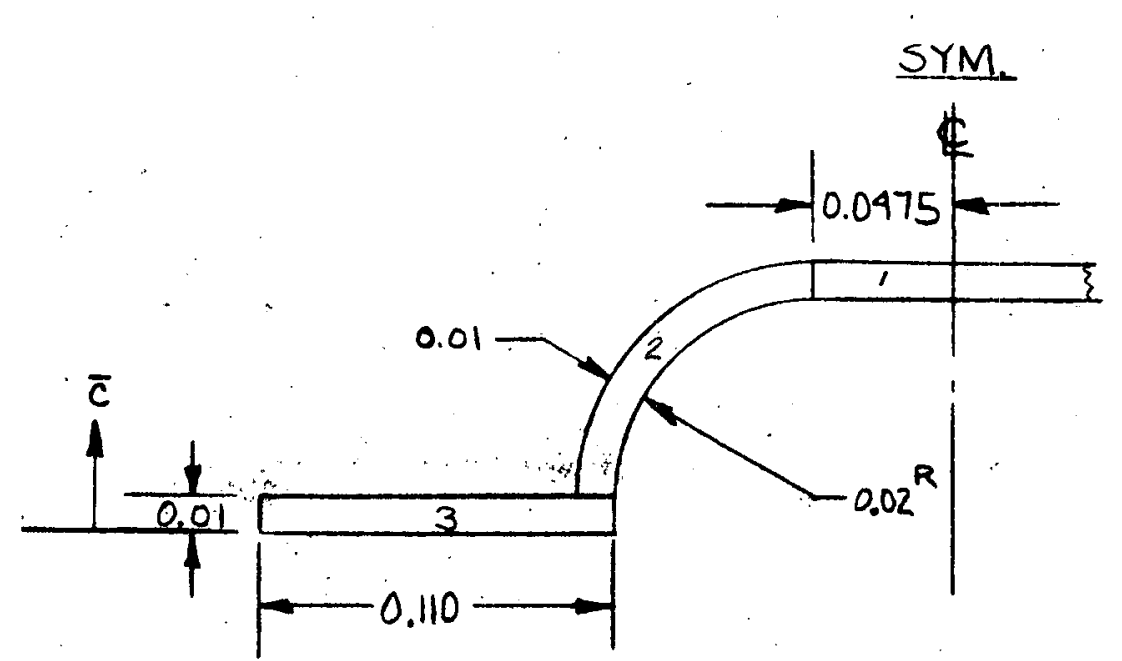

Centroid of Section

$$
\begin{aligned}
& A_{1}=.095 \times .01=9.5 \times 10^{-4} 1 \mathrm{n.}^{2} \\
& A_{2}=\frac{\pi}{2}\left(.03^{2}-.02^{2}\right)=7.85 \times 10^{-4} 1 \mathrm{n.} .^{2} \\
& A_{3}=.110 \times .01 \times 2=22 \times 10^{-4} 1 \mathrm{n}^{2} \\
& \bar{c}=\frac{22 \times 10^{-4} \times 5 \times 10^{-3}+9.5 \times 10^{-4} \times 35 \times 10^{-3}+7.85 \times 10^{-4} \times 2.61 \times 10^{-2}}{39.35 \times 10^{-4}} \\
& \bar{c}:=0.0164 \mathrm{1n} .
\end{aligned}
$$

Moment of Inertia of Section

$$
\begin{aligned}
& I_{1}=\frac{0.095 \times 0.01^{3}}{12}=7.91 \times 10^{-9} 1 \mathrm{n} .^{4} \\
& I_{2}=0.1098\left(R^{4}-r^{4}\right)-0.283 \frac{R^{2} r^{2}(R-r)}{R+r} \\
& I_{2}=0.1098(81-16) \times 10^{-8}-0.283 \frac{(9)(4) \times 10^{-8}}{5}
\end{aligned}
$$




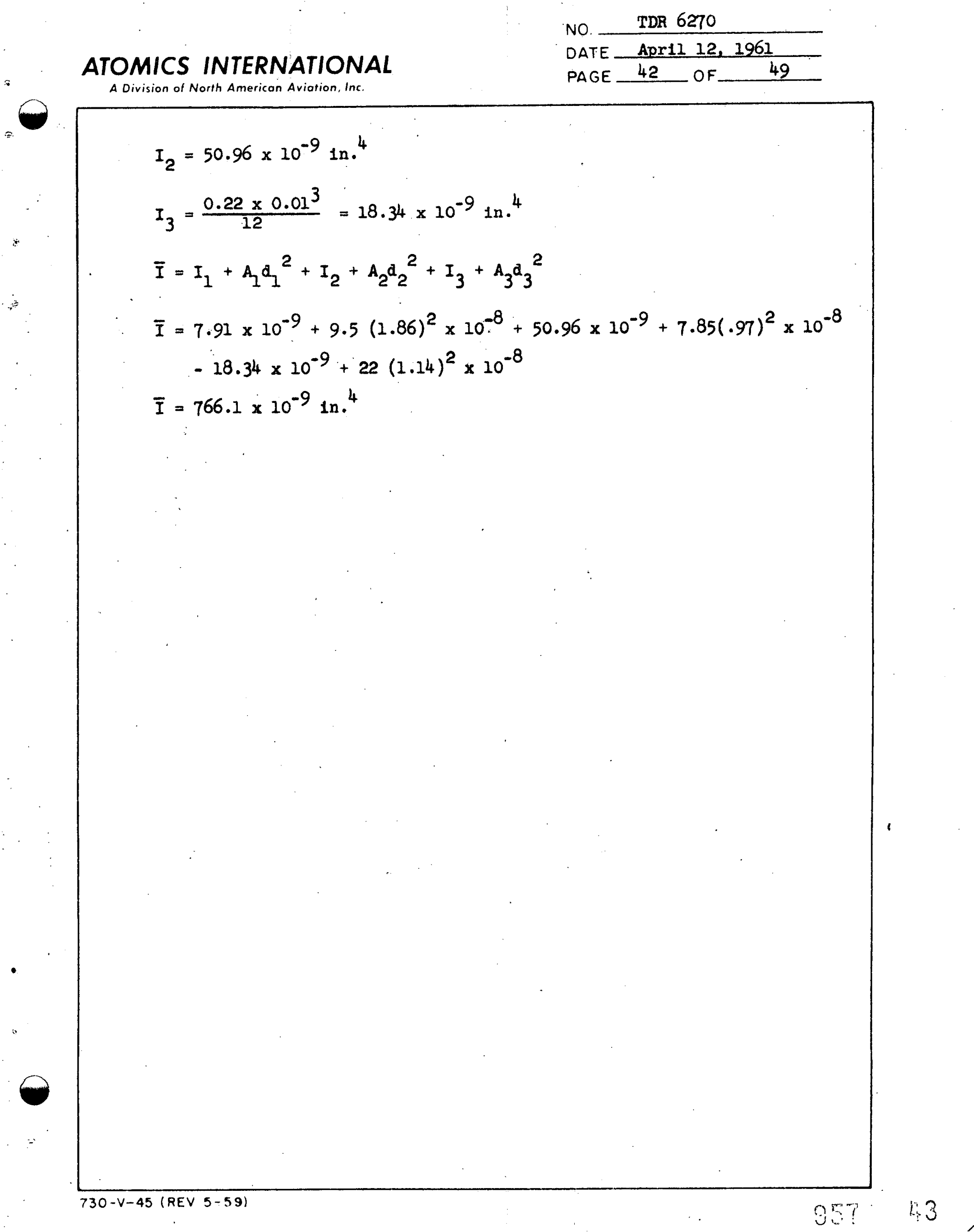




\section{APPEITDIX B}

Th1s appendix contains the following graphs:

1. Solution of the transcendental equation:

$$
\frac{[94.4-\mathrm{P}]}{562} \mathrm{P}^{\frac{1}{2}}=\tan 0.132 \mathrm{P}^{\frac{1}{2}}
$$

2. Solution of:

$$
m^{3}+2879 m^{2}+28.8 \times 10^{5} m=798 \times 10^{5}
$$

3. Stress-Creep Curve for 304 SS at 1000 F. (logarithmic plot)

4. Stress-Creep Curve for 304 SS at 1000 F. (I1near plot)

5. Plot of pressure bulld-up in rod with associated total accumulated strain as a function of time.

Assuming a linear relation between the stress vs creep rate curve in the range anelyzed (Graph 4)

$$
\nabla=a e+b
$$

where

$$
\begin{aligned}
& \nabla=\text { stress (ps1) } \\
& \text { e }=\text { creep rate (percent per hour) }
\end{aligned}
$$

when $\nabla=18300$

$$
\text { e }=1 \times 10^{-4}
$$

when $\nabla=21000 \mathrm{ps} 1$

$$
\begin{aligned}
& a=2.6 \times 10^{-4} \\
& 21000=2.6 \times 10^{-4} a+b \\
& 18300=1 \times 10^{-4} a+b
\end{aligned}
$$


ATOMICS INTERNATIONAL

A Division of North American Aviation, Inc.

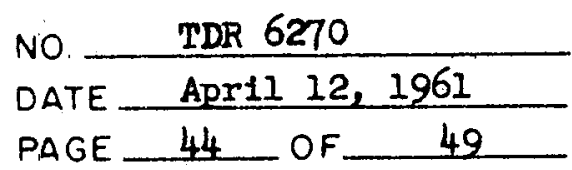

Subtracting

$$
\begin{aligned}
& 2700=1.6 \times 10^{-4} \\
& a=1.69 \times 10^{7} \frac{\text { hour-psi }}{\phi} \\
& b=16.61 \times 10^{3} \mathrm{ps1}
\end{aligned}
$$

Therefore:

$$
\nabla=1.69 \times 10^{7} \mathrm{e}+1.661 \times 10^{4}
$$

Changing to monthly basis

$$
\begin{aligned}
& \sigma=\frac{1.69 \times 10^{7} e}{720}+1.661 \times 10^{4} \\
& \sigma=2.35 \times 10^{4} e+1.661 \times 10^{4}
\end{aligned}
$$

where: e 18 now in $\%$ per month

and the units of $2.35 \times 10^{4}$ are $\frac{\text { psi-month }}{\phi}$

$730-V-45$ (REV 5-59) 

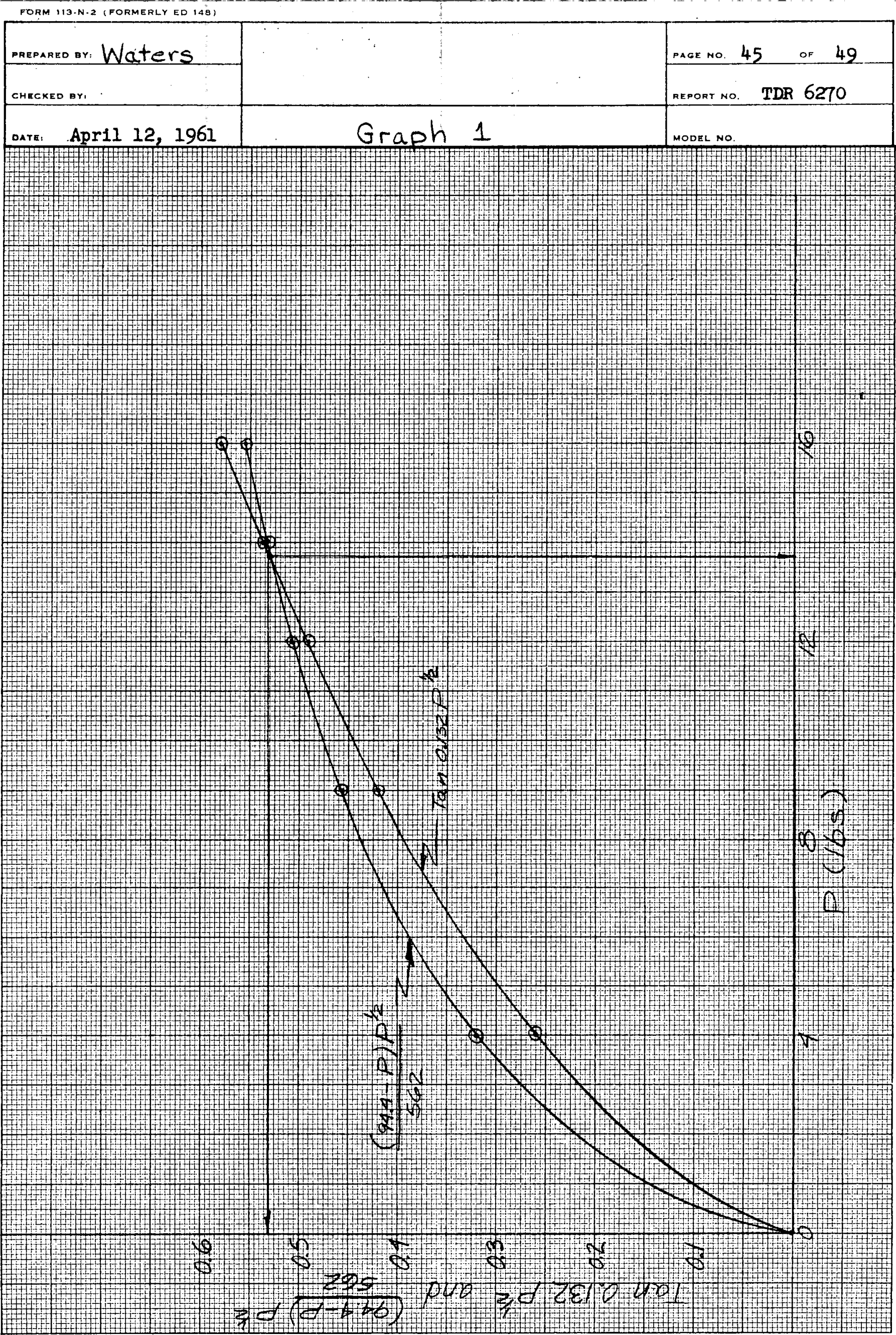


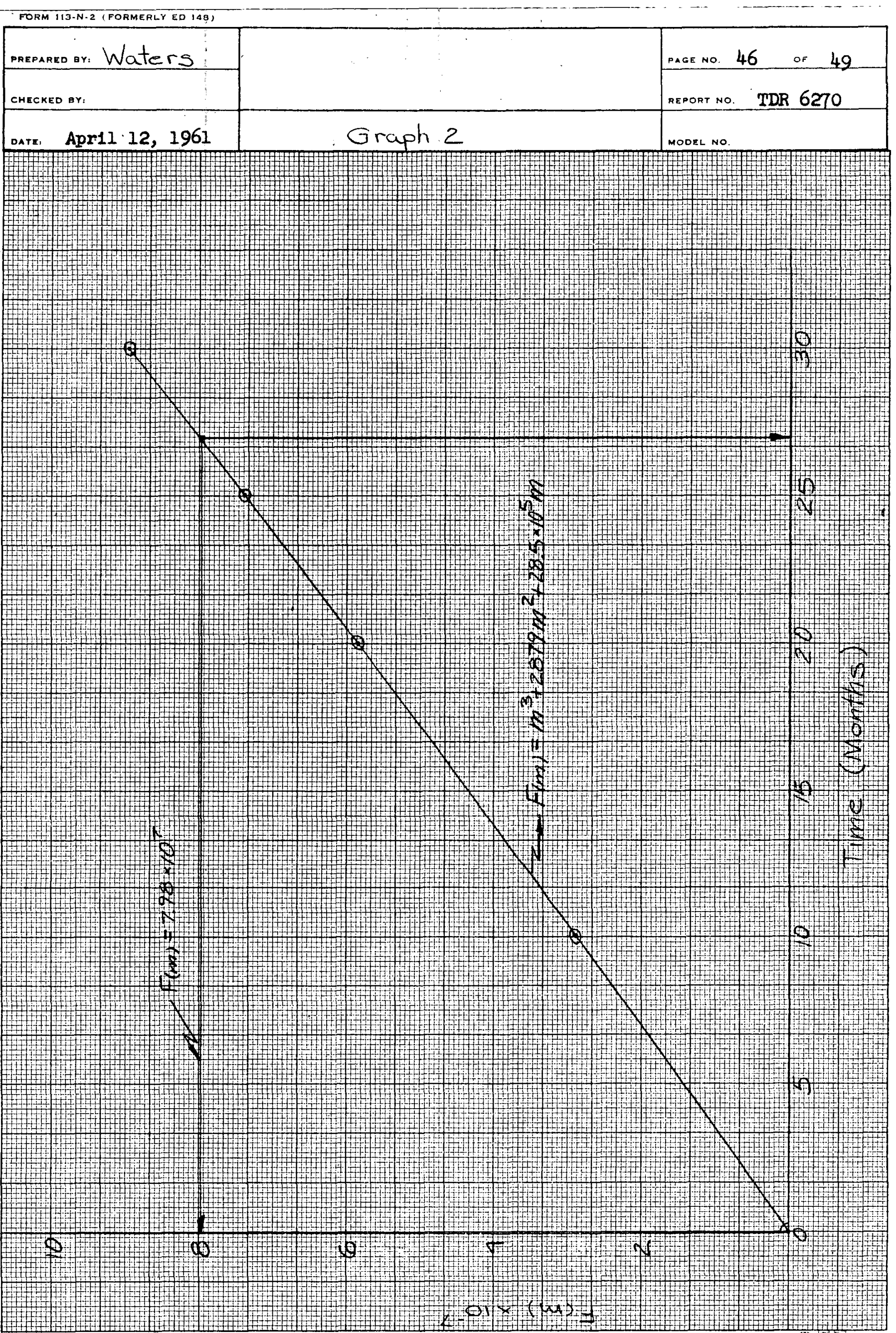




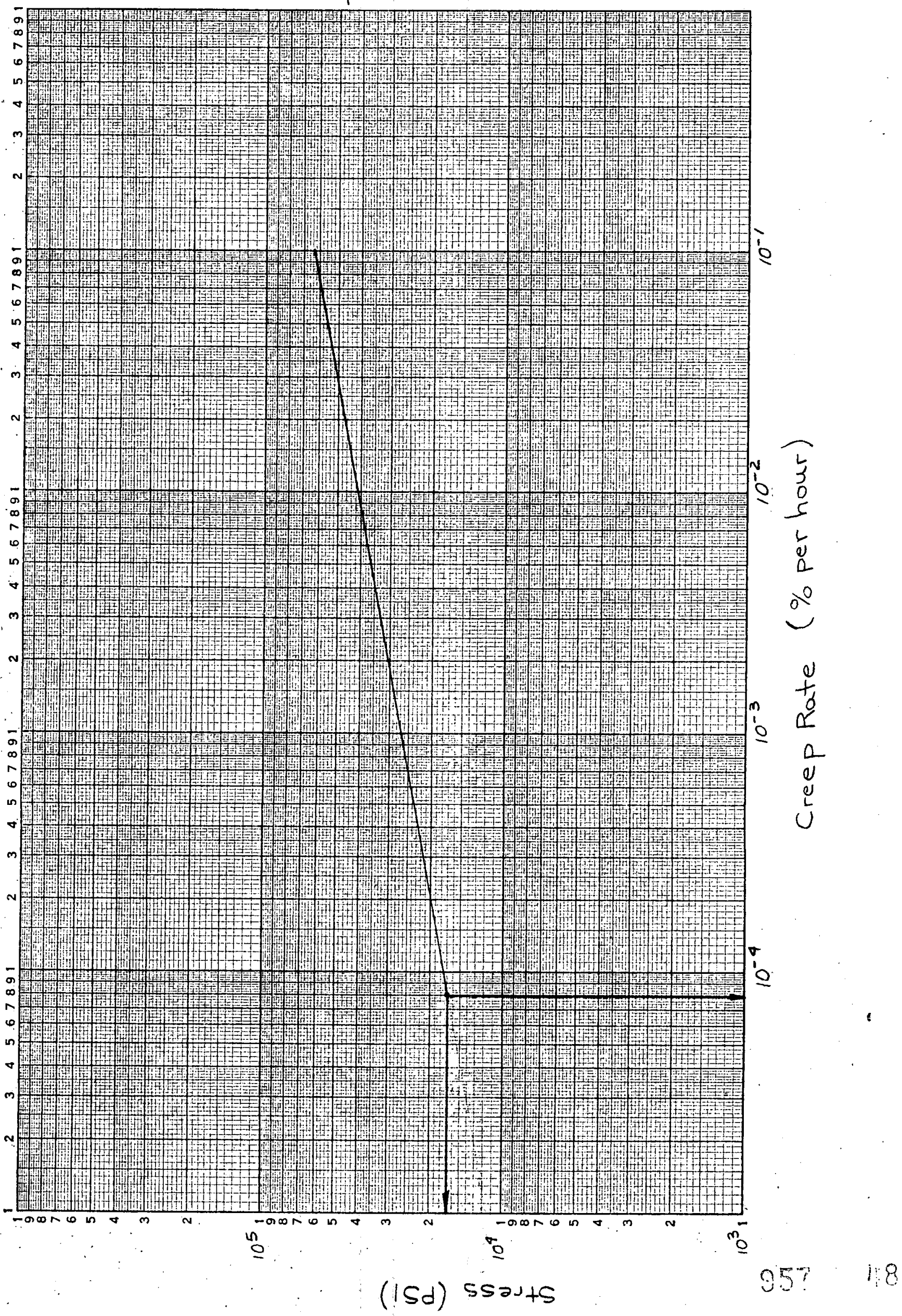




\section{S1}

$\$$

9

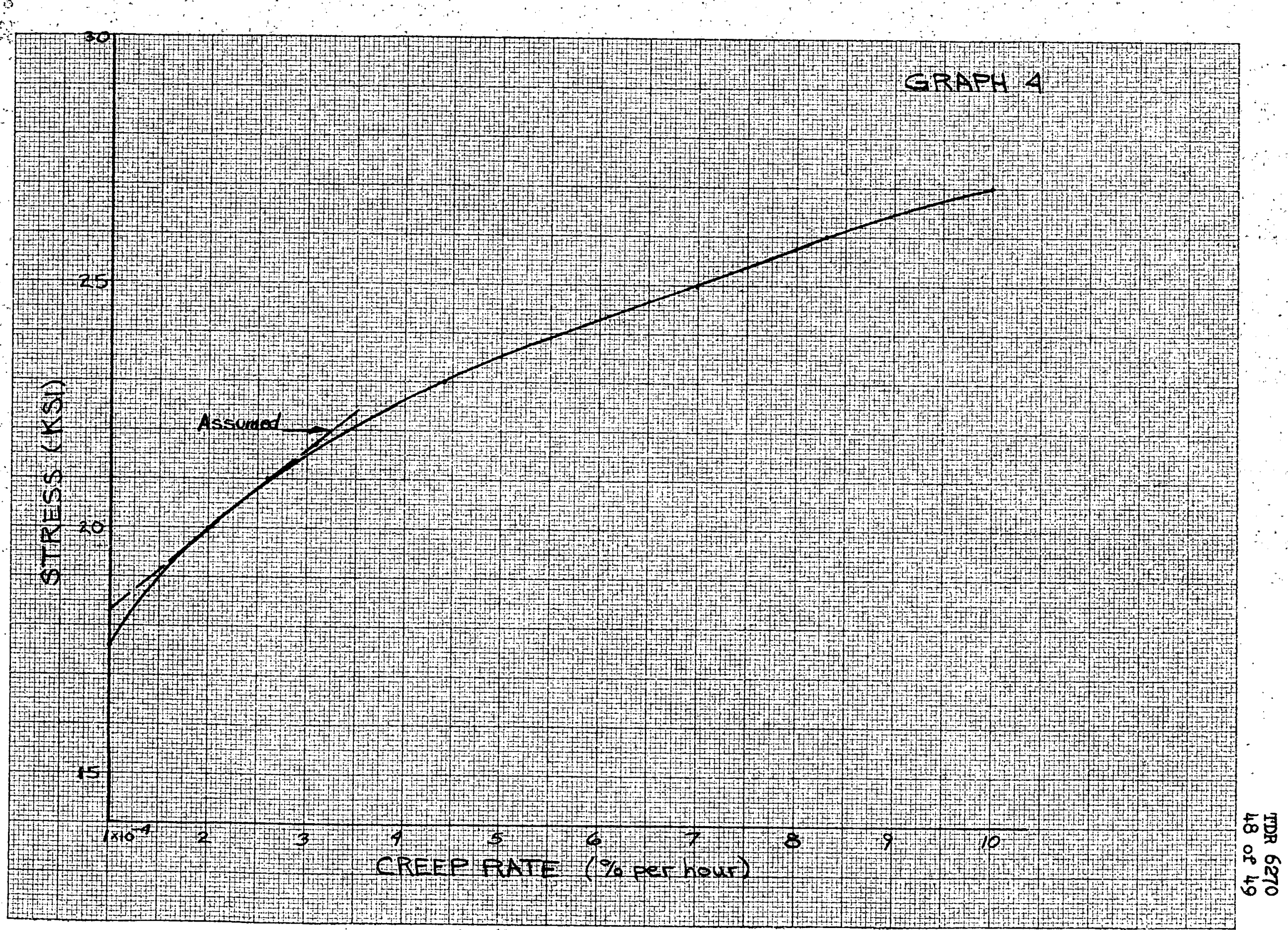




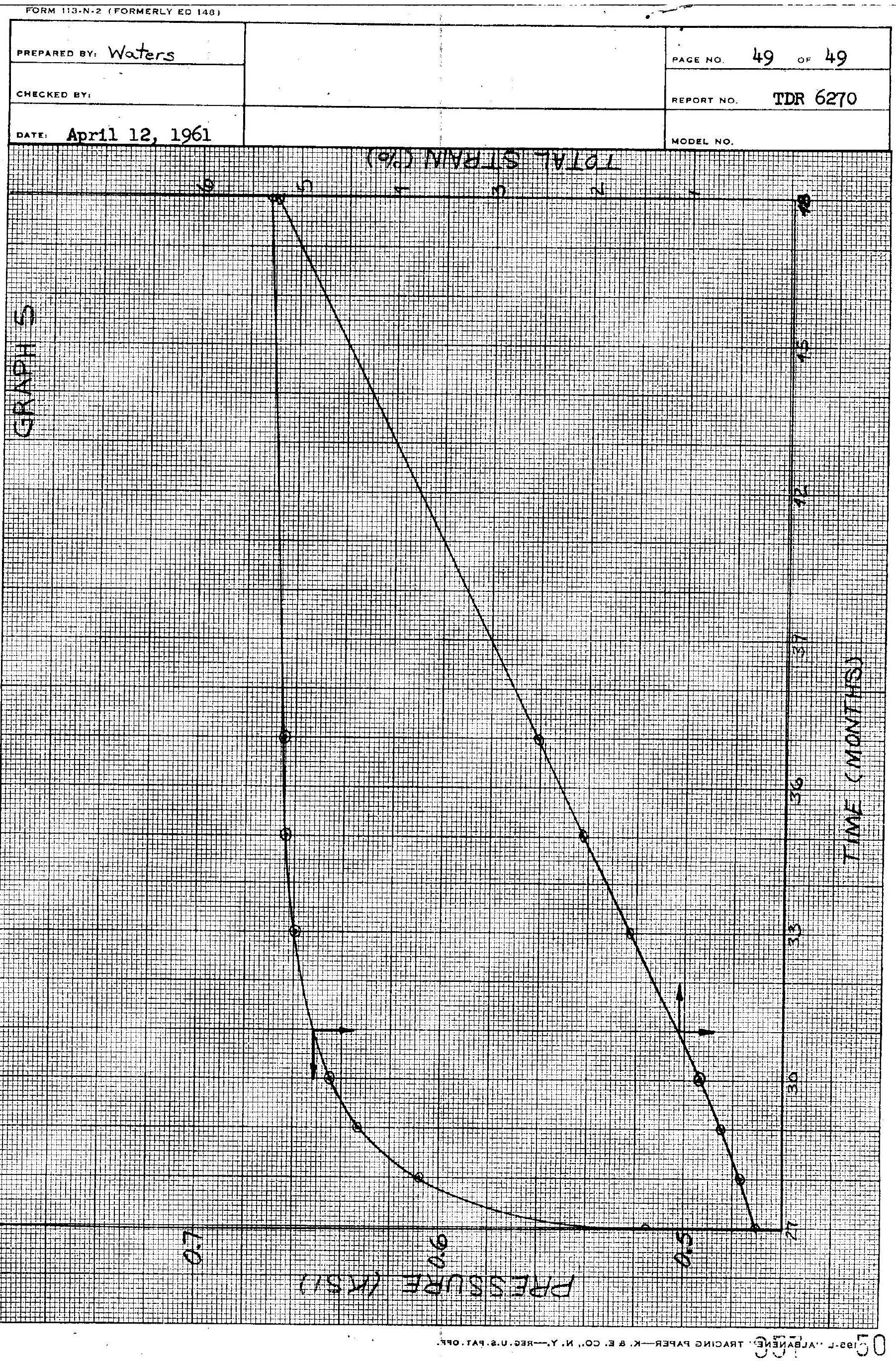

